This is an electronic reprint of the original article. This reprint may differ from the original in pagination and typographic detail.

\author{
Author(s): Nauha, Elisa; Saxell, Heidi; Nissinen, Maija; Kolehmainen, Erkki; Schäfer, Ansgar; \\ Schlecker, Rainer
}

Title: $\quad$ Polymorphism and versatile solvate formation of thiophanate-methyl

Year: $\quad 2009$

Version:

Please cite the original version:

Nauha, E., Saxell, H., Nissinen, M., Kolehmainen, E., Schäfer, A., \& Schlecker, R. (2009). Polymorphism and versatile solvate formation of thiophanate-methyl. CrystEngComm, 11, 2536-2547. https://doi.org/10.1039/B905511H

All material supplied via JYX is protected by copyright and other intellectual property rights, and duplication or sale of all or part of any of the repository collections is not permitted, except that material may be duplicated by you for your research use or educational purposes in electronic or print form. You must obtain permission for any other use. Electronic or print copies may not be offered, whether for sale or otherwise to anyone who is not an authorised user. 


\title{
Polymorphism and versatile solvate formation of thiophanate-methyl
}

\author{
Elisa Nauha $^{a}$, Heidi Saxell $^{b^{*}}$, Maija Nissinen $^{a}$, Erkki Kolehmainen $^{a}$, Ansgar Schäfer $^{b}$, Rainer Schlecker $^{b}$ \\ Receipt/Acceptance Data [DO NOT ALTER/DELETE THIS TEXT] \\ Publication data [DO NOT ALTER/DELETE THIS TEXT] \\ S DOI: 10.1039/b000000x [DO NOT ALTER/DELETE THIS TEXT]
}

The polymorphism of a fungicide, thiophanate-methyl (TM), was investigated with conventional solvent screening methods. Two polymorphs, the thermodynamically most stable form I and the less stable form II, were found. TM was also found to crystallize as plethora of different solvates which produced mostly form II upon desolvation. The structures of form I and form II and the

10 fourteen discovered solvates were solved by single crystal X-ray diffraction. The most stable forms were further characterized by powder diffraction, thermoanalytical (TG/DTA, DSC and thermomicroscopy) and spectroscopic (IR, Raman, ${ }^{13} \mathrm{C}$ CP/MAS NMR) methods.

\section{Introduction}

The growing field of crystal engineering deals with designing 15 and synthesizing molecular solid state structures with desired properties. $^{1}$ One approach to the subject is using supramolecular synthons ${ }^{2}$ composed of molecular fragments and the interactions between them to approximate the possible structural outcome of a crystal.

20 Polymorphism ${ }^{3}$, the ability of a compound to crystallize in more than one distinct crystal form, can be seen as a challenge in crystal engineering, but also as a means to investigate the principles of crystal formation as nature does it. In addition to polymorphs, a number of solvate forms with solvent 25 molecules included in the crystal lattice are commonly formed with the solvent of crystallization. ${ }^{4}$ These can further complicate the crystallization of compounds, but can also resolve some unanswered questions and be, for instance, routes to other crystal forms, not easily reached otherwise. ${ }^{5}$

30 The solvent molecules in the crystal structure may either be included to decrease void space in the crystal or be for example hydrogen bonded to the molecules of the compound to better satisfy the possible intermolecular interactions. ${ }^{6}$ The occurance of polymorphs and solvates is especially high 35 amongst molecules with flexible torsions and several low energy conformers. ${ }^{7}$

The literature reflects the importance of polymorphism in

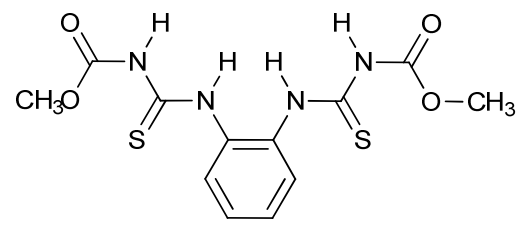

Scheme 1 The molecular structure of TM.

\footnotetext{
${ }^{a}$ Department of Chemistry, Nanoscience Center, P.O. Box 35, FIN-40014 University of Jyväskylä, Finland. Fax: +358 14260 4756; Tel: +358 14 260 4242; E-mail: maija.j.nissinen@jyu.fi

${ }^{b}$ BASF SE, GVC - A030, D-67056, Ludwigshafen, Germany. Fax: +49 621 60-20440; Tel: +4962160-49558; E-mail: heidi.saxell@basf.com $\uparrow$ Electronic Supplementary Information (ESI) available: DSC and TGA/DTA curves, hydrogen bonding parameters, temperature variable $\mathrm{CP} / \mathrm{MAS}$ NMR, calculated PXRDs and additional structural pictures. See http://dx.doi.org/10.1039/b000000x/
}

pharmaceutical substances. ${ }^{3}$ The basic questions in agrochemical actives ${ }^{8}$ are essentially the same; how many 40 forms can be found and what are properties and thermodynamical relationships of the forms.

We carried out conventional solvent screening investigating the polymorphism of a pesticide active, thiophanate-methyl (TM) (Scheme 1), dimethyl 4,4'-(o-phenylene)bis(345 thioallophanate), which is relatively flexible and capable of forming multiple hydrogen bonds as well as aromatic interactions. The motivation was to investigate whether the variation in melting points reported in the literature $\left(135^{\circ} \mathrm{C}\right.$ to $200^{\circ} \mathrm{C}^{9}$ ) is due to the existance of different polymorphs of $50 \mathrm{TM}$, and on the other hand whether these forms exhibit varying hydrogen bonding arrangements. Recently, multi component crystals, co-crystals, of TM have been reported with different agrochemical actives. ${ }^{10}$

$\mathrm{TM}$ is a fungicide and wound protectant and has been used, 55 for example, in protecting citrus fruits against post harvest decay in packing houses. ${ }^{11} \mathrm{TM}$ belongs to a group of fungicides that transform into benzimidazoles during use with TM specifically transforming into carbendazim. ${ }^{11,12}$ Benzimidazoles work by impairing microtubule growth in 60 fungal cells, which consequently prevents correct cell division, as microtubules are needed in forming the spindle that guides the movement of chromosomes during cell division. $^{13}$

\section{Experimental}

${ }_{65}$ Materials. TM of $99.8 \%$ purity from BASF, distilled water and solvents of analytical purity (min 99\%) were used in the crystallization experiments.

Crystallizations. The used solvents included water, acetone, acetonitrile $(\mathrm{MeCN})$, THF, methanol $(\mathrm{MeOH})$, ethanol $70(\mathrm{EtOH})$, chloroform, dichloromethane (DCM), 1,2dichloroethane (1,2-DCE), dioxane, pyridine, 1,2dichlorobenzene (1,2-DCB), benzene, cyclohexanone, DMSO, dimethylacetamide (DMA), methyl isobutyl ketone and 1,2propanediol. Amounts of 0.5 to $1.0 \mathrm{~g}$ of TM were dissolved in 7515 to $100 \mathrm{ml}$ of solvent with the help of an ultrasonic water bath $\left(\sim 40^{\circ} \mathrm{C}\right)$. If the entire sample did not dissolve, solutions were filtered through a Witeg Por.2 glass filter. The solutions 
were allowed to evaporate at RT until crystals formed. The crystallizations from acetonitrile, DMA and methyl isobutyl 80 ketone produced form I, while all other crystallizations produced solvates. Form II was acquired by fast crystallization from acetone under reduced pressure and a single crystal was acquired from a 1:1 mixture of acetonitrile and water. Slow cooling crystallizations produced the same 85 results.

Thermomicroscopy. The behavior of crystals during heating was studied under polarized light with a Mettler FP82HT hot stage connected to a Mettler FP90 central processor with an Olympus BH-2 microscope. The primary heating rate used 90 was $10^{\circ} \mathrm{C} / \mathrm{min}$ from $30^{\circ} \mathrm{C}$ to melting/decomposition of the sample at around $170^{\circ} \mathrm{C}$.

TG/DTA. Thermogravimetric/differential thermal analyses were carried out with a Mettler Toledo TGA/SDTA 851 using $\mathrm{Al}_{2} \mathrm{O}_{3}$ as reference. The samples $(8-22 \mathrm{mg})$ were placed in ${ }_{95}$ platinum sample pans for measurement with a temperature program from 30 to $605^{\circ} \mathrm{C}$ at $10^{\circ} \mathrm{C} / \mathrm{min}$ and $\mathrm{N}_{2}$ gas flow.

DSC. Differential scanning calorimetric determinations were made on a Mettler Toledo DSC 823e with TS0801RO Sample Robot and TS08006C1 Gas Control. The measurements of 100 form I and form II were done with three different heating rates $\left(5,10\right.$ and $20{ }^{\circ} \mathrm{C} / \mathrm{min}$ ) from 30 to $185^{\circ} \mathrm{C}$ using aluminum crucibles with pinholes.

Single crystal X-ray diffraction. X-ray diffraction data was collected graphite-monochromated $\mathrm{CuK} \alpha$ radiation $(\lambda=$ $1051.54178 \AA$ ). The data for TM form I, the methanol, ethanol, DCM, 1,2-DCE, cyclohexanone, DMSO, THF, dioxane, pyridine, 1,2-DCB and benzene solvates was collected at 103 $\mathrm{K}$ on a Bruker AXS CCD Detector. The data for TM form II, the chloroform and acetone solvate and the acetonitrile solvate 110 mono hydrate was collected with a Nonius Kappa CCD diffractometer with Apex II detector at $173 \mathrm{~K}$. The structures were solved with direct methods, refined, and expanded by using Fourier techniques with the SHELX-97 software package $^{14}$. Absorption correction was performed with ${ }_{115}$ SADABS $^{15}$ or Denzo-SMN v0.97.638 ${ }^{16}$. Hydrogen atoms were placed in idealized positions ( $\mathrm{C}-\mathrm{H}$ hydrogens) or found from the electron density map (most $\mathrm{N}-\mathrm{H}$ hydrogens) and included in structure factor calculations. The N-H distances of the hydrogen bonding hydrogens were restrained to $0.91 \AA$ to

120 give the best fit to the $\mathrm{X}$-ray data and to ensure a stable refinement. The WinGX program system ${ }^{17}$ and the Shelxtl program package ${ }^{18}$ were used. Residual electron density in the DMSO solvate that could be assigned to severely disordered DMSO molecules was removed with the program ${ }_{125}$ SQUEEZE $^{19}$. The quality of the ethanol solvate structure solution is poor and thus only preliminary data is given. The methanol in the methanol solvate is disordered over two postions and could only be refined isotropically without hydrogen atoms. The poor quality of several of the structures 130 is due to insufficient data collection as the structures were measured for industrial purposes. Pictures of the structures were drawn with Mercury ${ }^{20}$. Crystal data and collection parameters of the structures are presented in Tables 1 and 2.

PXRD. Powder X-ray diffraction patterns were measured with 135 a Siemens D5000 X-ray diffractometer with a $\mathrm{Cu}$ anode $(\lambda=$ $1.5406 \AA ; 45 \mathrm{kV}, 25 \mathrm{~mA}$ ). The measurement temperature was $25^{\circ} \mathrm{C}(\mathrm{RT})$ and a $2 \theta$-angle range of $5-35^{\circ}$ and a step resolution of $0.020^{\circ}$ was used with a step time of $4.5 \mathrm{~s}$.

${ }^{13}$ C CP/MAS NMR. The ${ }^{13} \mathrm{C}$ CP/MAS NMR spectra were 140 measured with a Bruker Avance 400 FT NMR spectrometer with a dual $4 \mathrm{~mm} \mathrm{CP} / \mathrm{MAS}$ probehead. The sample was packed in a $4 \mathrm{~mm}$ diameter $\mathrm{ZrO}_{2}$ rotor, which was spun at 10 $\mathrm{KHz}$ rate at 296 or $373 \mathrm{~K}$. Contact time for CP was $4 \mathrm{~ms}$, pulse interval $4 \mathrm{~s}$, time domain $2 \mathrm{~K}$, which was zero filled to 8 ${ }_{145} \mathrm{~K}$ in frequency domain. Exponential window function with 5 $\mathrm{Hz}$ line broadening was used. 20000 scans were acquired.

IR and Raman spectroscopy. The IR spectra were measured from $\mathrm{KBr}$ tablets on a Thermo Nicolet Nexus 470 IR spectrometer with a DTGS $\mathrm{KBr}$ detector. The Raman spectra 150 were measured with a Nicolet 950 FT-Raman spectrometer.

Isothermal microcalorimetry. The dissolution energy of form I and form II was measured on a Thermometric Precision Solution Calorimeter at $25^{\circ} \mathrm{C}$ with $100 \mathrm{ml}$ of DMSO and 200 mg of TM.

${ }_{155}$ Calculation of gasphase conformers. The conformer screening was performed by a hierarchical procedure. First all possible combinations of dihedral angles were generated to define a first set of 2916 structures. For these structures molecular energies were calculated using the Dreiding force 160 field $^{21}$ in combination with the charge equilibration method ${ }^{22}$ (charges determined for the initial starting structure were kept fixed). All structures within the first $10000 \mathrm{kcal} / \mathrm{mol}$ were extracted and checked for redundancies, which resulted in an intermediate set of 1716 structures. This first part was carried 165 out with tools in the Cerius ${ }^{2}$ program $^{23}$. For the intermediate set of structures geometry optimizations were performed on the density functional theory level using the B-P functional ${ }^{24}$ and TZVP basis $\operatorname{sets}^{25}$ in the RI approximation ${ }^{26}$. After removal of redundant structures, 215 distinct conformers were 170 left, which were verified as energy minima by analytical second derivatives of the energy with respect to nuclear positions. The final ranking of conformers was done based on second-order Møller-Plesset perturbation theory (MP2) energy calculations in the RI approximation ${ }^{27}$ using TZVPP basis $175 \mathrm{sets}^{28}$. The DFT and MP2 calculations were done with the Turbomole program package ${ }^{29}$.

\section{Results and discussion}

\section{Polymorphs}

Two polymorphs of TM were found and characterized. Form $180 \mathrm{I}$, of which the original commercially available sample was composed of, crystallized from acetonitrile solution (also from DMA, methyl isobutyl ketone and 1,2-propanediol solutions) and form II, or a mixture of form I and form II, was acquired mostly by desolvation of the found solvates. Pure powdered 185 samples of form II were obtained by reduced pressure evaporation from warm acetone solutions of TM followed by heating at $80^{\circ} \mathrm{C}$ in a vacuum oven for one hour. Form II was also found to crystallize from acetonitrile:water $(1: 1, \mathrm{~V}: \mathrm{V})$ solution, though not consistently. The next paragraphs 190 describe the crystal structures of both polymorphs. The differences in the conformations of TM are discussed later in the chapter "conformations". 


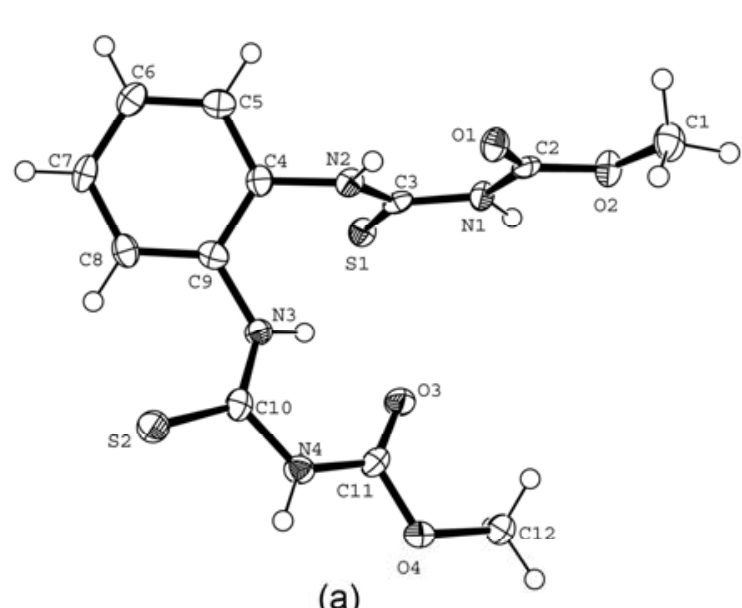

(a)

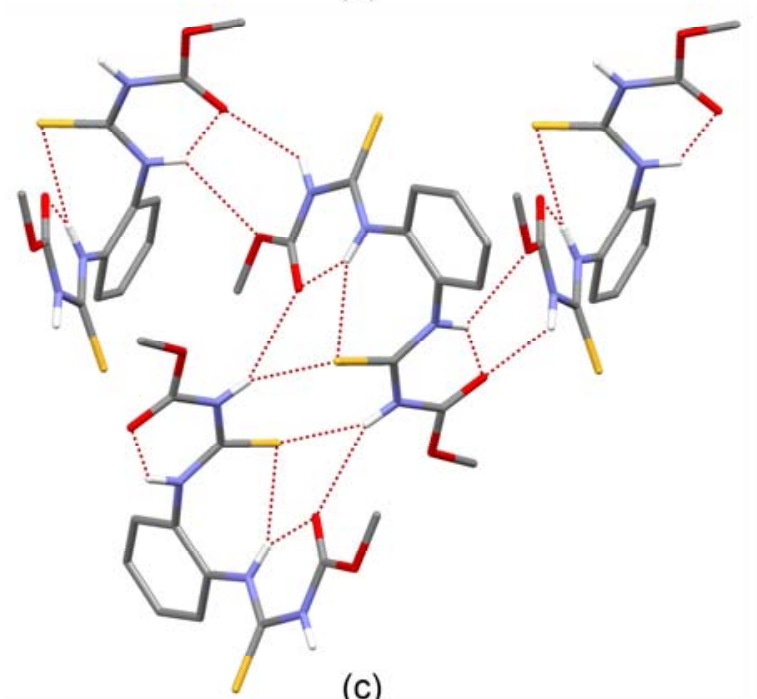

(c)

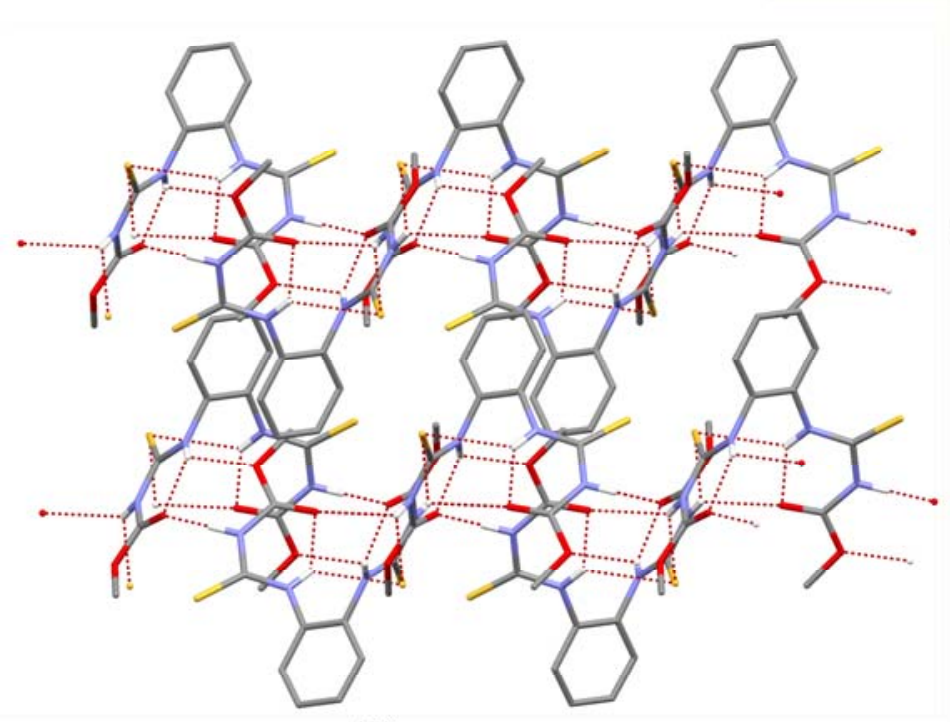

(e)

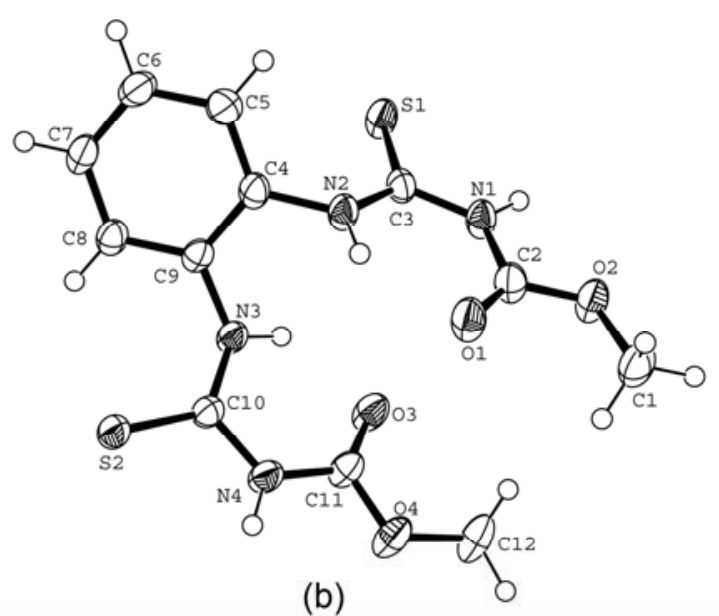

(b)

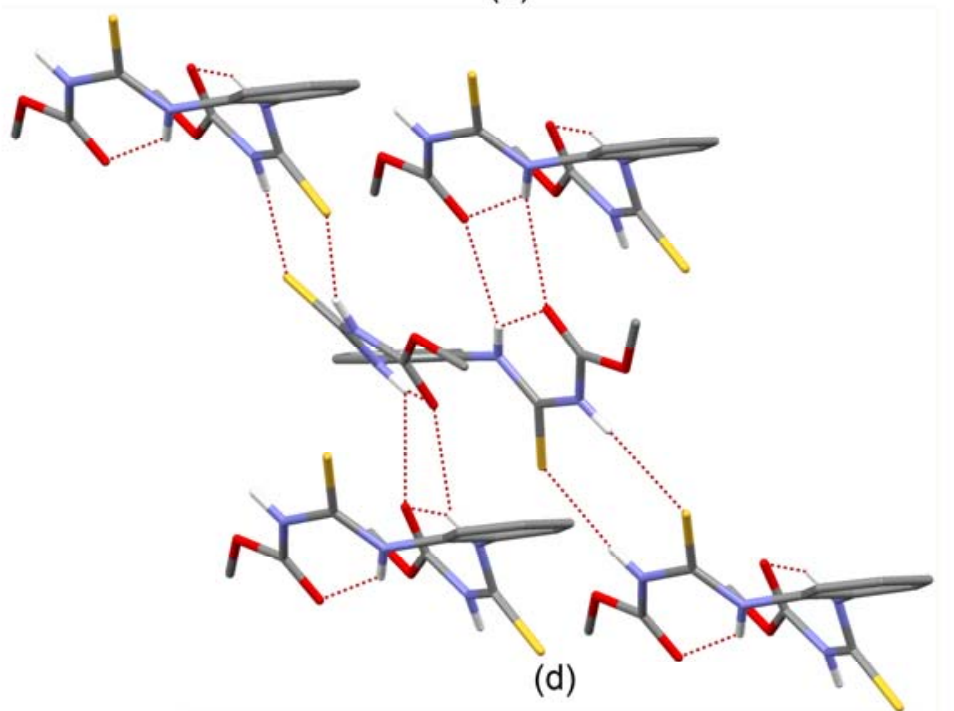

(d)

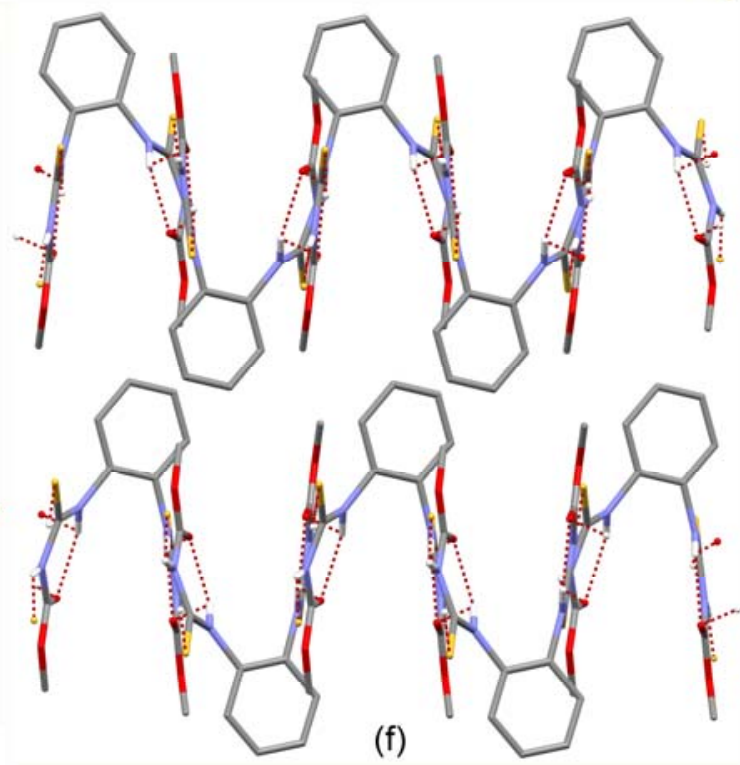

Fig. 1 Ortep plots of (a) form I and (b) form II with the numbering of the atoms in the molecules of TM and hydrogen bonding of TM molecules in (c) form I and (d) form II, and two-dimensional sheets TM molecules viewed from the side in (e) form I and (f) form II. Non-hydrogen bonding hydrogens are omitted for clarity from (c)-(f).

\section{Crystal structure of form I}

Block crystals of form I crystallized from acetonitrile solution 195 in the monoclinic space group $\mathrm{P} 2{ }_{1} / \mathrm{n}$ with one $\mathrm{TM}$ molecule in the asymmetric unit (Fig. 1a). In the crystal structure one molecule of TM is hydrogen bonded with 8 hydrogen bonds in all to three adjacent molecules of TM. In addition, there are 
three intramolecular hydrogen bonds of which one $(\mathrm{N}-$ $200 \mathrm{H} \cdots \mathrm{S}=\mathrm{C}$ bond) joins the two arms, i.e. the two functional groups on the benzene ring of the molecule, and the other two $(\mathrm{N}-\mathrm{H} \cdots \mathrm{O}=\mathrm{C}$ bonds) are within the arms (Fig. 1c).

Two types of inter-molecular hydrogen bond arrangements are found in the structure (bonding parameters in ESI). The

205 first is composed of one $\mathrm{N}-\mathrm{H} \cdot \bullet \mathrm{O}=\mathrm{C}$ bond and one $\mathrm{N}-\mathrm{H} \cdot \bullet \mathrm{O}-\mathrm{C}$ hydrogen bond and causes infinite chains of TM (the top three TM molecules in Fig. 1c). These chains are then connected by hydrogen bonds to parallel chains with a hand-in-hand arrangement that binds a pair of molecules together. This 210 pairing arrangement (the bottom and central molecule in Fig. 1c) consists of intra- and intermolecular bifurcated N$\mathrm{H} \cdots \mathrm{S}=\mathrm{C}$ and $\mathrm{N}-\mathrm{H} \cdots \mathrm{O}=\mathrm{C}$ hydrogen bonds. With this arrangement, every other molecule in the infinite chains is connected to one adjacent chain and every other molecule to 215 another adjacent chain. The framework of connected chains produces infinite two-dimensional sheets (Fig. 1e). Aromatic and methyl groups point outward from the sheets making hydrophobic layers that facilitate the stacking of the sheets.

\section{Crystal structure of form II}

220 Block crystals of form II were found to crystallize from a
Table 1 Crystal data and collection parameters for form I and form II

\begin{tabular}{|c|c|c|}
\hline & Form I & Form II \\
\hline $\begin{array}{l}\text { Formula } \\
\end{array}$ & $\mathrm{C}_{12} \mathrm{H}_{14} \mathrm{~N}_{4} \mathrm{O}_{4} \mathrm{~S}_{2}$ & $\mathrm{C}_{12} \mathrm{H}_{14} \mathrm{~N}_{4} \mathrm{O}_{4} \mathrm{~S}_{2}$ \\
\hline M & 342.39 & 342.39 \\
\hline Crystal system & Monoclinic & Monoclinic \\
\hline Space group & $\mathrm{P} 2_{1} / \mathrm{c}$ & $\mathrm{P} 2{ }_{1} / \mathrm{c}$ \\
\hline $\mathrm{a}(\AA)$ & $10.7149(5)$ & $8.946(2)$ \\
\hline $\mathrm{b}(\AA)$ & $11.8405(5)$ & $20.052(4)$ \\
\hline c $(\AA)$ & $15.6861(6)$ & $8.998(2)$ \\
\hline$\beta(\operatorname{deg})$ & $132.593(2)$ & 107.51(3) \\
\hline$V\left(\AA^{3}\right)$ & $1465.1(2)$ & $1539.3(5)$ \\
\hline Z & 4 & 4 \\
\hline$\rho_{\text {calc }}\left(\mathrm{g} / \mathrm{cm}^{3}\right)$ & 1.552 & 1.477 \\
\hline Meas reflns & 9507 & 4338 \\
\hline Indp reflns & 1744 & 2653 \\
\hline $\mathrm{R}_{\text {int }}$ & 0.0572 & 0.0449 \\
\hline $\mathrm{R}_{1}[\mathrm{I}>2 \sigma(\mathrm{I})]$ & 0.0402 & 0.0424 \\
\hline $\mathrm{wR}_{2}[\mathrm{I}>2 \sigma(\mathrm{I})]$ & 0.1128 & 0.1119 \\
\hline GooF & 1.187 & 1.055 \\
\hline
\end{tabular}

acetonitrile:water (1:1) solution in the monoclinic space group $\mathrm{P} 2{ }_{1} / \mathrm{c}$ with one molecule of TM in the asymmetric unit (Fig. 1b). In this structure one TM molecule is hydrogen bonded with 8 hydrogen bonds in all to four adjacent TM molecules 225 (Fig. 1d). There is also intramolecular $\mathrm{N}-\mathrm{H} \bullet \bullet \mathrm{O}=\mathrm{C}$ hydrogen

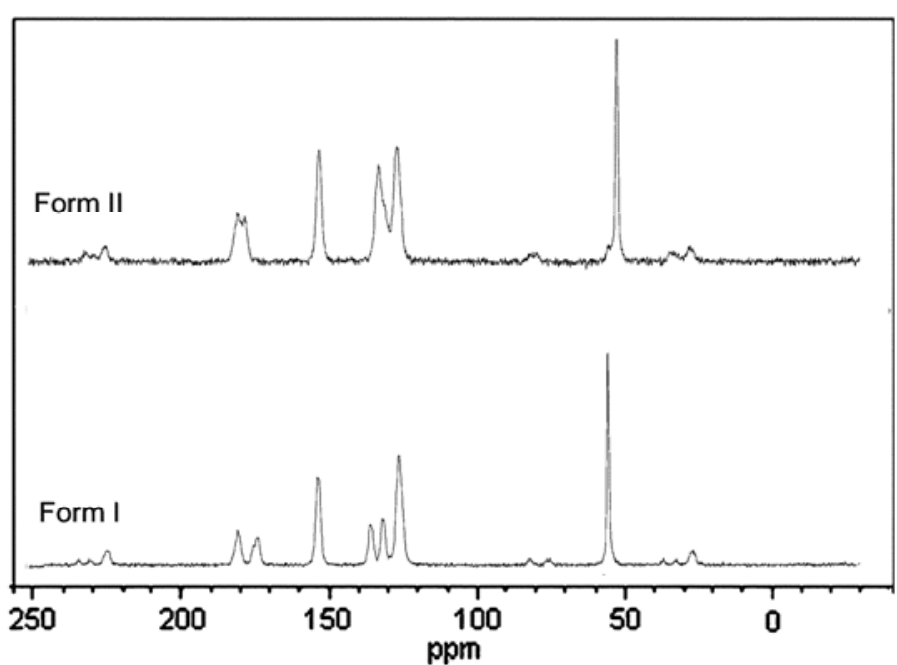

(b)

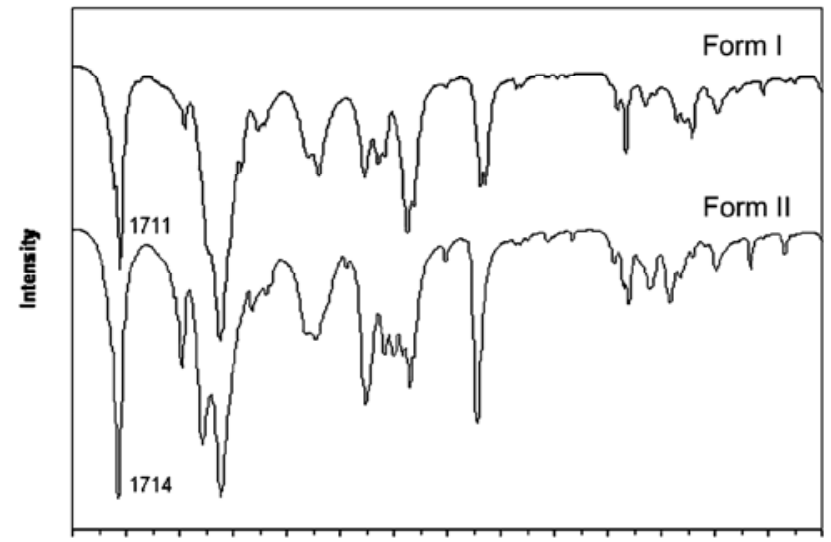

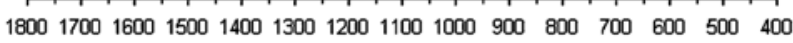
Wavenumber

(c)

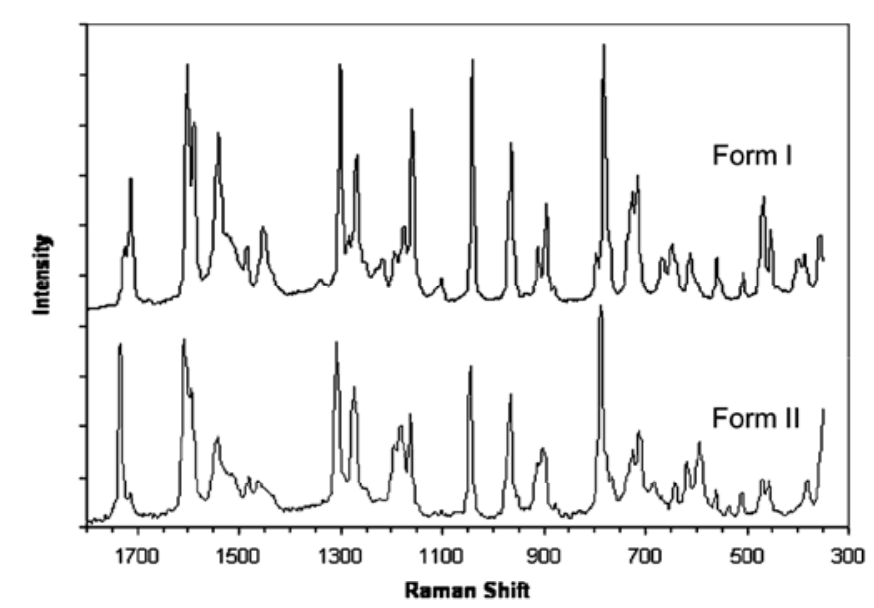

(d)

Fig. 2 (a) PXRD patterns (b) ${ }^{13} \mathrm{C}$ CP/MAS NMR spectra, (c) IR and (d) Raman spectra of forms I and II. 
bonding within the arms of the molecule.

The TM molecules are connected with two different hydrogen bonding arrangements - one with two $\mathrm{N}-\mathrm{H} \cdot \bullet \mathrm{S}=\mathrm{C}$ and one with two $\mathrm{N}-\mathrm{H} \cdot \cdots \mathrm{O}=\mathrm{C}$ hydrogen bonds. These 230 arrangements produce infinite two dimensonal sheets of TM molecules (Fig. 1f) that then stack up on each other like those in form I with hydrophobic interactions between the methyl and benzene groups.

\section{Further characterization}

${ }_{235}$ The polymorphs were also characterized with PXRD, DSC, TG/DTA, thermomicroscopy, CP/MAS NMR, IR and Raman methods. In the DSCs (ESI) of both forms decomposition started at around $165^{\circ} \mathrm{C}$ with peak maxima at $174.2^{\circ} \mathrm{C}$ and $175.9^{\circ} \mathrm{C}$ for form I and form II, respectively. In the DSC of 240 form I there is additionally a very small endothermic peak at around $115^{\circ} \mathrm{C}$, which showed up at all heating rates and is possibly explained by impurities as at that temperature there is no change observed with the thermomicroscope with which form I and fom II could not be distinguished. The TG/DTA
245 (ESI) curves of the two polymorphs were also practically indistinguishable.

The PXRD patterns (Fig. 2a) of the two polymorphs can be clearly distinguished. PXRD patterns were thus used for form identification in further experiments. (Comparisons between 250 experimental and calculated PXRD patterns in ESI).

Forms I and II can also be distinguished from their ${ }^{13} \mathrm{C}$ CP/MAS NMR spectra (Fig. 2b). The methyl group peaks are at $55.1 \mathrm{ppm}$ for form I and $52.2 \mathrm{ppm}$ for form II with a small peak at $55.0 \mathrm{ppm}$, indicating that the methyl groups are in 255 somewhat different environments in the two forms. The peaks of the ester carbon atoms are at $153.2 \mathrm{ppm}$ and $153.1 \mathrm{ppm}$ for form I and form II, respectively, and thus are in very similar environments. The benzene carbon peaks are different for the two forms and point to 3 types of environments for form I and 260 two types of environments for form II. By comparing the chemical shifts of the corresponding $\mathrm{C}=\mathrm{S}$ carbon atoms, it can be concluded that the $\mathrm{C}=\mathrm{S}$ carbons with peaks at around 180 ppm are in more similar surroundings in form II than in form I

Table 2 Crystal data and collection parameters for the solvate crystal forms of TM

\begin{tabular}{|c|c|c|c|c|c|c|c|}
\hline & $\mathrm{MeCN} / \mathrm{H}_{2} \mathbf{O}^{a}$ & DCM & 1,2-DCE & Methanol $^{a}$ & Ethanol $^{b}$ & Acetone & Cyclohexanone \\
\hline \multirow{2}{*}{ Formula } & $3 \mathrm{C}_{12} \mathrm{H}_{14} \mathrm{~N}_{4} \mathrm{O}_{4} \mathrm{~S}_{2}$ & $\mathrm{C}_{12} \mathrm{H}_{14} \mathrm{~N}_{4} \mathrm{O}_{4} \mathrm{~S}_{2}$ & $\mathrm{C}_{12} \mathrm{H}_{14} \mathrm{~N}_{4} \mathrm{O}_{4} \mathrm{~S}_{2}$ & $2 \mathrm{C}_{12} \mathrm{H}_{14} \mathrm{~N}_{4} \mathrm{O}_{4} \mathrm{~S}_{2}$ & $2 \mathrm{C}_{12} \mathrm{H}_{14} \mathrm{~N}_{4} \mathrm{O}_{4} \mathrm{~S}_{2}$ & $2 \mathrm{C}_{12} \mathrm{H}_{14} \mathrm{~N}_{4} \mathrm{O}_{4} \mathrm{~S}_{2}$ & $2 \mathrm{C}_{12} \mathrm{H}_{14} \mathrm{~N}_{4} \mathrm{O}_{4} \mathrm{~S}_{2}$ \\
\hline & $\cdot 2.5 \mathrm{C}_{2} \mathrm{H}_{3} \mathrm{~N} \cdot \mathrm{H}_{2} \mathrm{O}$ & $\cdot \mathrm{CH}_{2} \mathrm{Cl}_{2}$ & $\cdot \mathrm{C}_{2} \mathrm{H}_{4} \mathrm{Cl}_{2}$ & $\cdot \mathrm{CH}_{3} \mathrm{OH}$ & $\cdot \mathrm{CH}_{3} \mathrm{CH}_{2} \mathrm{OH}$ & $\cdot\left(\mathrm{CH}_{3}\right)_{2} \mathrm{CO}$ & $\cdot \mathrm{C}_{6} \mathrm{H}_{10} \mathrm{O}$ \\
\hline $\mathrm{M}$ & 1147.83 & 427.32 & 441.34 & 719.83 & 730.85 & 742.86 & 782.92 \\
\hline Crystal system & Triclinic & Triclinic & Triclinic & Triclinic & Triclinic & Triclinic & Triclinic \\
\hline Space group & P-1 & P-1 & P-1 & P-1 & P-1 & P-1 & P-1 \\
\hline $\mathrm{a}(\AA)$ & $10.641(2)$ & $9.313(6)$ & $9.313(2)$ & $10.016(3)$ & $9.842(2)$ & $10.206(2)$ & $11.277(3)$ \\
\hline b $(\AA)$ & $13.751(3)$ & $10.145(6)$ & $10.150(2)$ & $11.430(3)$ & $11.370(2)$ & $11.153(2)$ & $17.368(4)$ \\
\hline c $(\AA)$ & $20.181(4)$ & $10.777(7)$ & $10.735(2)$ & $15.904(5)$ & $15.988(3)$ & $17.062(3)$ & $19.902(5)$ \\
\hline$\alpha(\mathrm{deg})$ & $74.62(3)$ & $83.04(4)$ & $82.06(2)$ & $101.73(1)$ & $78.99(1)$ & $76.69(3)$ & $92.21(2)$ \\
\hline$\beta$ (deg) & $85.49(3)$ & $80.00(4)$ & $79.40(2)$ & $90.33(1)$ & $89.34(1)$ & $86.07(3)$ & $103.76(2)$ \\
\hline$\gamma(\operatorname{deg})$ & $77.97(3)$ & $80.12(4)$ & $79.41(2)$ & 107.692(9) & $72.15(2)$ & $72.46(3)$ & $100.77(1)$ \\
\hline$V\left(\AA^{3}\right)$ & $2784(1)$ & $984(2)$ & $974.7(4)$ & $1694.0(9)$ & $1669.5(5)$ & $1802.0(6)$ & $3705(2)$ \\
\hline $\mathrm{Z}$ & 2 & 2 & 2 & 2 & 2 & 2 & 4 \\
\hline$\rho_{\text {calc }}\left(\mathrm{g} / \mathrm{cm}^{3}\right)$ & 1.369 & 1.443 & 1.504 & 1.405 & 1.454 & 1.369 & 1.404 \\
\hline Meas reflns & 12985 & 3274 & 8006 & 7891 & 9780 & 8844 & 28524 \\
\hline Indp reflns & 9441 & 1992 & 2410 & 3543 & 3869 & 6210 & 9162 \\
\hline $\mathrm{R}_{\text {int }}$ & 0.0832 & 0.0490 & 0.0450 & 0.0606 & 0.0660 & 0.1118 & 0.0473 \\
\hline $\mathrm{R}_{1}[\mathrm{I}>2 \sigma(\mathrm{I})]$ & 0.0719 & 0.0680 & 0.0358 & 0.0726 & 0.1717 & 0.0487 & 0.0411 \\
\hline $\mathrm{wR}_{2}[\mathrm{I}>2 \sigma(\mathrm{I})]$ & 0.1748 & 0.1767 & 0.0910 & 0.1975 & 0.4942 & 0.1271 & 0.0938 \\
\hline \multirow[t]{2}{*}{ GooF } & 1.062 & 1.037 & 1.059 & 1.104 & 2.166 & 1.022 & 1.038 \\
\hline & DMSO $^{c}$ & Chloroform & THF & Dioxane & Pyridine & 1,2-DCB & Benzene \\
\hline Formula & $\begin{array}{l}\mathrm{C}_{12} \mathrm{H}_{14} \mathrm{~N}_{4} \mathrm{O}_{4} \mathrm{~S}_{2} \\
\cdot \mathrm{C}_{2} \mathrm{H}_{6} \mathrm{OS}\end{array}$ & $\begin{array}{l}\mathrm{C}_{12} \mathrm{H}_{14} \mathrm{~N}_{4} \mathrm{O}_{4} \mathrm{~S}_{2} \\
\text { - } \mathrm{CHCl}_{3}\end{array}$ & $\begin{array}{l}\mathrm{C}_{12} \mathrm{H}_{14} \mathrm{~N}_{4} \mathrm{O}_{4} \mathrm{~S}_{2} \\
\cdot \mathrm{C}_{4} \mathrm{H}_{8} \mathrm{O}\end{array}$ & $\begin{array}{l}\mathrm{C}_{12} \mathrm{H}_{14} \mathrm{~N}_{4} \mathrm{O}_{4} \mathrm{~S}_{2} \\
\cdot \mathrm{C}_{4} \mathrm{H}_{8} \mathrm{O}_{2}\end{array}$ & $\begin{array}{l}\mathrm{C}_{12} \mathrm{H}_{14} \mathrm{~N}_{4} \mathrm{O}_{4} \mathrm{~S}_{2} \\
\cdot \mathrm{C}_{5} \mathrm{H}_{5} \mathrm{~N}\end{array}$ & $\begin{array}{l}\mathrm{C}_{12} \mathrm{H}_{14} \mathrm{~N}_{4} \mathrm{O}_{4} \mathrm{~S}_{2} \\
\text { - } \mathrm{C}_{6} \mathrm{H}_{4} \mathrm{Cl}_{2}\end{array}$ & $\begin{array}{l}\mathrm{C}_{12} \mathrm{H}_{14} \mathrm{~N}_{4} \mathrm{O}_{4} \mathrm{~S}_{2} \\
\cdot \mathrm{C}_{6} \mathrm{H}_{6}\end{array}$ \\
\hline M & 420.52 & 461.76 & 414.52 & 430.50 & 421.49 & 489.38 & 420.50 \\
\hline Crystal system & Monoclinic & Triclinic & Triclinic & Monoclinic & Triclinic & Triclinic & Triclinic \\
\hline Space group & $\mathrm{C} 2 / \mathrm{c}$ & P-1 & P-1 & $\mathrm{C} 2 / \mathrm{c}$ & P-1 & P-1 & P-1 \\
\hline $\mathrm{a}(\AA)$ & $26.52(2)$ & $10.626(2)$ & $10.546(2)$ & $21.97(1)$ & $8.244(1)$ & $7.9951(7)$ & $8.4106(8)$ \\
\hline $\mathrm{b}(\AA)$ & $10.321(5)$ & $14.706(3)$ & $14.470(3)$ & $11.428(5)$ & $10.690(2)$ & $9.5484(9)$ & $9.9524(9)$ \\
\hline c $(\AA)$ & $17.43(1)$ & $14.739(3)$ & $14.592(2)$ & $17.147(7)$ & $12.493(2)$ & $14.702(2)$ & $12.952(2)$ \\
\hline$\alpha(\mathrm{deg})$ & 90 & $63.51(3)$ & $65.317(8)$ & 90 & $67.892(5)$ & $81.910(4)$ & $107.946(4)$ \\
\hline$\beta$ (deg) & $94.66(3)$ & $77.34(3)$ & $77.66(1)$ & $111.24(2)$ & $81.442(6)$ & $84.862(4)$ & $101.732(5)$ \\
\hline$\gamma(\operatorname{deg})$ & 90 & $74.82(3)$ & $76.29(1)$ & 90 & $74.153(5)$ & $73.646(4)$ & $96.983(4)$ \\
\hline $\mathrm{V}\left(\AA^{3}\right)$ & $4755(5)$ & $1975.6(7)$ & $1948.8(6)$ & $4014(3)$ & $979.9(2)$ & $1064.7(2)$ & $991.0(2)$ \\
\hline $\mathrm{Z}$ & 8 & 4 & 4 & 8 & 2 & 2 & 2 \\
\hline$\rho_{\text {calc }}\left(\mathrm{g} / \mathrm{cm}^{3}\right)$ & 1.175 & 1.552 & 1.4013 & 1.425 & 1.429 & 1.526 & 1.409 \\
\hline Meas reflns & 12637 & 10630 & 9286 & 7583 & 7870 & 7159 & 8528 \\
\hline Indp reflns & 3184 & 6828 & 4514 & 2484 & 2437 & 2645 & 2494 \\
\hline $\mathrm{R}_{\text {int }}$ & 0.1367 & 0.0679 & 0.0407 & 0.0475 & 0.0321 & 0.0323 & 0.0313 \\
\hline $\mathrm{R}_{1}[\mathrm{I}>2 \sigma(\mathrm{I})]$ & 0.0899 & 0.0557 & 0.0526 & 0.0679 & 0.0434 & 0.0459 & 0.0373 \\
\hline $\mathrm{wR}_{2}[\mathrm{I}>2 \sigma(\mathrm{I})]$ & 0.2145 & 0.1358 & 0.1494 & 0.1866 & 0.1082 & 0.1127 & 0.0889 \\
\hline GooF & 0.988 & 1.027 & 1.123 & 1.079 & 1.167 & 1.201 & 1.106 \\
\hline
\end{tabular}

${ }^{a}$ The $\mathrm{H}_{2} \mathrm{O} / \mathrm{MeOH}$ hydrogen atoms could not be accurately placed, ${ }^{b}$ Preliminary data, ${ }^{c}$ Due to the removal of a disordered DMSO molecule by Squeeze ${ }^{17}$ the chemical formula, molecular weight and density are not accurate. 
since the peak separation is bigger in the spectrum of form I.

${ }_{265}$ From the crystal structures one can see the reason for this as in form I only one sulfur seems to be involved in hydrogen bonding and in form II both sulfurs are hydrogen bonded. Also because in form II both $\mathrm{C}=\mathrm{S}$ carbon chemical shifts are deshielded in comparison to those in form I, one can conclude 270 from the CP/MAS NMR spectrum that in form II both $\mathrm{C}=\mathrm{S}$ groups are hydrogen bonded. ${ }^{30}$

There are differences in the IR and Raman spectra (Fig. 2c and d) of the two forms, but these were not investigated further due to PXRD being such a good method to 275 differentiate the two forms. The IR rule ${ }^{31}$ can be used to determine the stability order of polymorphs. The first absorption band of carbonyl oxygen atoms in the fingerprint region for form I is at $1711 \mathrm{~cm}^{-1}$ and for form II at $1714 \mathrm{~cm}^{-1}$. The difference is small and inconsistent with other data as it 280 indicates form II being more stable. This difference of $3 \mathrm{~cm}^{-1}$ could also indicate greater involvement of the carbonyl oxygen atoms of form I in intermolecular interactions.

\section{Transformation and stability}

According to thermal analysis the relationship between the 285 two polymorphs is monotropic, as no endothermic (or exothermic) transition is observed for either form. Temperature variable ${ }^{13} \mathrm{C} \mathrm{CP} / \mathrm{MAS} \mathrm{NMR}$ (form II, RT to $100^{\circ} \mathrm{C}$ ) and PXRD (form I, RT to $130^{\circ} \mathrm{C}$ ) analyses also indicate no transformations. However, no melting temperature 290 could be determined and no heat-of-fusion could be measured because of the decomposition of TM and thus the heat-offusion rule ${ }^{31}$ could not be used to back up our interpretation.

Form I has a calculated density of $1.51 \mathrm{~g} / \mathrm{cm}^{3}$ and form II $1.46 \mathrm{~g} / \mathrm{cm}^{3}$. According to the density rule ${ }^{31}$ the denser ${ }_{295}$ polymorph, in this case form I, is more stable at absolute zero. As the relationship between the polymorphs is monotropic, form $I$ is also more stable at all temperatures. The energies of dissolution, measured by solution microcalorimetry, were $4.011 \mathrm{~kJ} / \mathrm{mol}$ for form I and $-6.724 \mathrm{~kJ} / \mathrm{mol}$ for form II. 300 According to the results, form I is approximately $2.7 \mathrm{~kJ} / \mathrm{mol}$ lower in energy than form II. Form II also converts to form I when mixed in a suspension of water and in water-glycerol mixtures, giving further evidence of the stability of form I.
The solution-mediated transformation from form I to form II 305 occurred faster at elevated temperatures $\left(80^{\circ} \mathrm{C}\right)$ than at room temperature indicating form I to be more stable also at higher temperatures.

\section{Solvates}

Fourteen solvates of TM (acetonitrile/water, methanol, 310 ethanol, acetone, DMSO, cyclohexanone, dichloromethane, 1,2-dichloroethane, dioxane, pyridine, 1,2-dichlorobenzene, THF, chloroform and benzene) were encountered during the investigations (Table 3). All but the acetonitrile solvate monohydrate crystallized quite consistently from solutions of 315 the corresponding solvents. Crystal structures of all the found solvates were determined. The hydrogen bonding networks and packing of the solvates is complex, as can be expected by the various hydrogen bonding possibilities and the vast amount of low energy conformers offered by TM. We do not 320 feel that a detailed analysis is necessary here. However, we try to bring up some common features and categorize the structures where applicable.

\section{Stability and desolvation behavior}

When taken out of solution, the solvates desolvate at 325 temperatures from room temperature (RT) to around $130^{\circ} \mathrm{C}$, as determined by thermomicroscopy (HS) and TG/DTA (Table 3). Most of the solvates also desolvate quite rapidly at room temperature when left out of solution, though the methanol and ethanol solvates seem to be rather stable and stay solvated 330 for weeks even when out of solution. Upon desolvation (in a vacuum oven at temperatures of $80-130^{\circ} \mathrm{C}$ depending on the desolvation temperature of the solvate) the tested solvates produce form II or a mixture of form I and form II, as determined with PXRD. According to the experiments, a 335 correlation could not be recognized between the structure of the solvated or the desolvation temperature and the preferred desolvation product, even though the acetone, DCM, THF and chloroform solvates, which desolvate even at room temperature, appear to produce preferentially only form II. 340 The reason for the emergence of mixtures may be solventmediated transformation occurring when the solvent does not leave from around the crystals as they desolvate.

\section{Hand-in-hand pairs}

Table 3 Habits, ratios of TM to solvent from TGA data, desolvation temperatures and the forms after desolvation of the found solvates

\begin{tabular}{|c|c|c|c|c|c|c|}
\hline \multirow[t]{2}{*}{ Solvate } & \multirow[t]{2}{*}{ Habit } & \multirow[t]{2}{*}{ Ratio } & \multicolumn{2}{|c|}{ Desolvation T $\left({ }^{\circ} \mathbf{C}\right)$} & \multirow[t]{2}{*}{ After desolvation } & \multirow[t]{2}{*}{ Solvent BP } \\
\hline & & & HS & TGA & & \\
\hline DCM & Blocks & $1: 1$ & $<75$ & - & Form II & 39.8 \\
\hline 1,2-DCE & Blocks & $1: 1$ & 72 & 73 & Form II \& Form I & 83.5 \\
\hline Acetonitrile/water & Needles & $1: 1^{a}$ & RT & - & - & 82 \\
\hline Methanol & Plates & $2: 1$ & 131 & 148 & Form II \& Form I & 64.7 \\
\hline Ethanol & Plates & $2: 1$ & 130 & 140 & Form I \& Form II & 78.4 \\
\hline Cyclohexanone & Plates/rods & $2: 1$ & 109 & 112 & Form I \& Form II & 155.7 \\
\hline DMSO & Plates/blocks & $1: 1(1: 2)^{b}$ & $71-130$ & 88 & Form II \& Form I & 189 \\
\hline THF & Rods & $1: 1$ & $<84$ & 76 & Form II & 66 \\
\hline Dioxane & Blocks & $1: 1$ & 80 & 111 & Form II \& Form I & 101.1 \\
\hline Pyridine & Irregular blocks & $1: 1$ & 85 & 125 & Form II & 115.2 \\
\hline 1,2-DCB & Blocks & $1: 1$ & 62 & - & Form I \& Form II & 180.5 \\
\hline Benzene & Blocks/plates & $1: 1$ & 58 & - & - & 80.1 \\
\hline Acetone & Plates & $2: 1$ & 84 & 83 & Form II & 56.3 \\
\hline Chloroform & Needles/rods & $1: 1(2: 1)^{\mathrm{c}}$ & $<60$ & 63 & Form II & 61.2 \\
\hline
\end{tabular}

${ }^{a}$ More precisely 3:2.5:1 (TM:MeCN:H2 $\mathrm{H}_{2}{ }^{b}$ The TM to DMSO ratio of 1:2 from the structure solution disagrees with the TGA result of 1:1 because of overlaps in the TGA due to the high boiling point of DMSO and the comparitatively low desolvation point of the DMSO solvate ${ }^{\mathrm{c}}$ The TGA result of 2:1 disagrees with that of the structure solution most likely due to partial desolvation before analysis. 


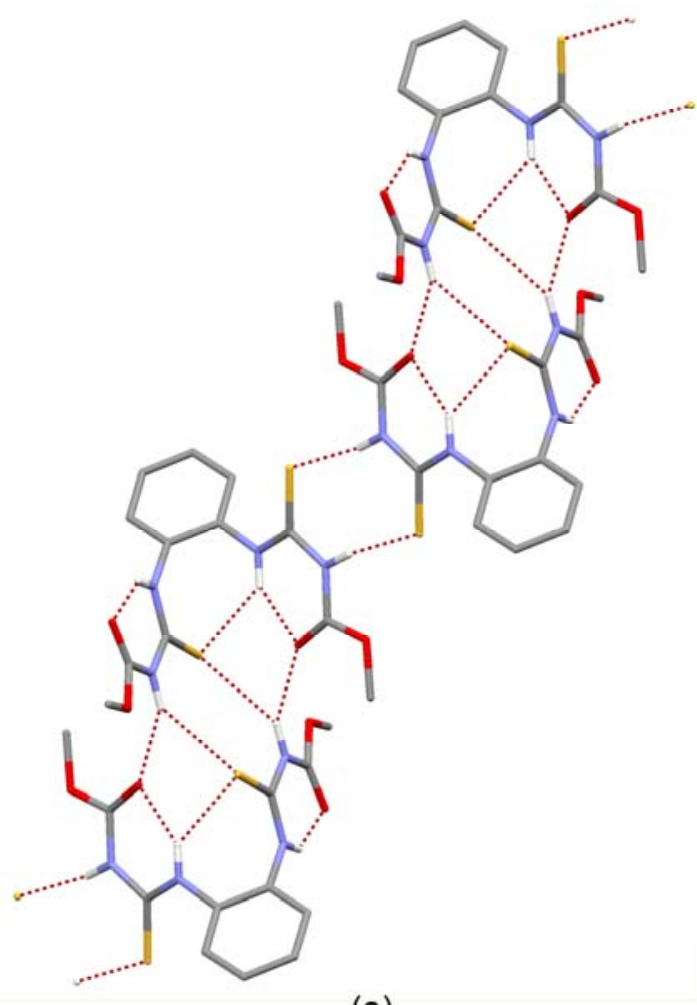

(a)

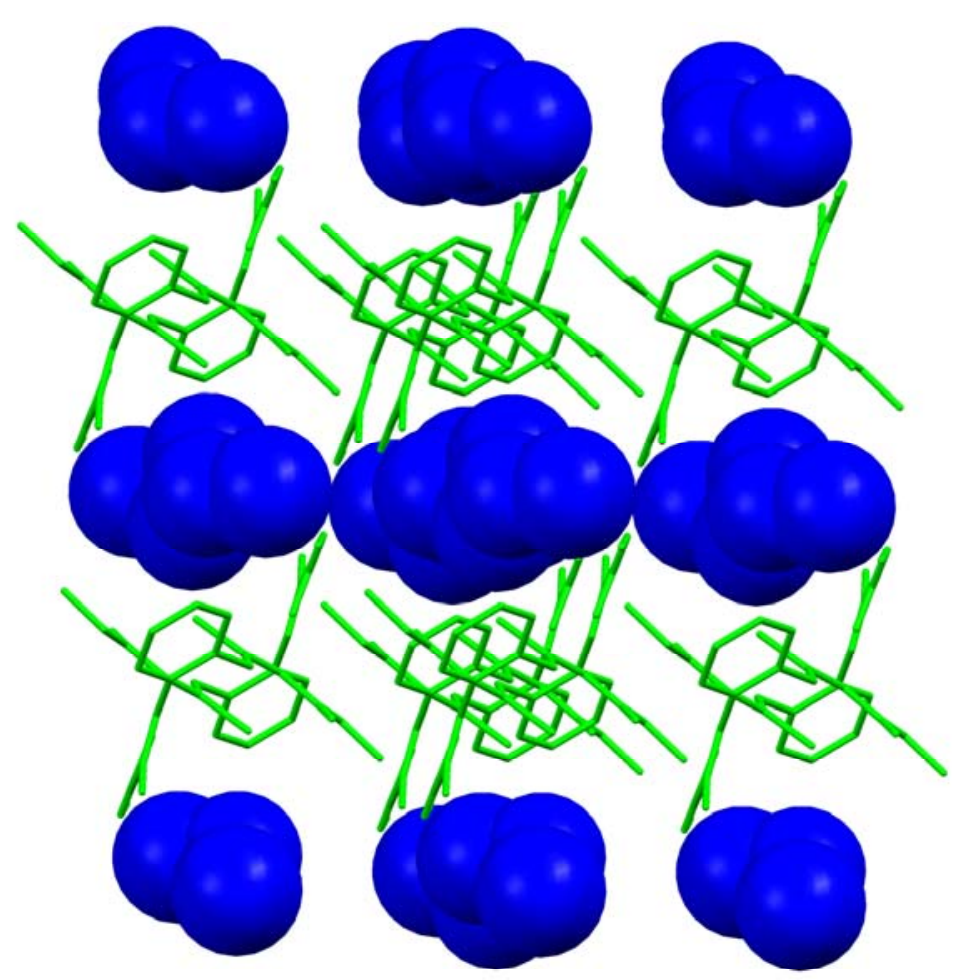

(b)

Fig. 3 (a) Hydrogen bonding of TM in the DCM and 1,2-DCE solvates (from the DCM solvate) and (b) solvent channels in the DCM solvate with the DCM molecules in spacefill style. Non H-bonding hydrogens are omitted for clarity.

The dichloromethane and 1,2-dichloroethane solvates are 345 isomorphic and crystallize from the respective solvents by evaporation and cooling crystallization in the triclinic space group P-1 with one molecule of TM and one solvent molecule in the asymmetric unit. The TM molecules arrange in hand-inhand pairs like the ones in form I. The pairs, however, are 350 connected to each other with two $\mathrm{N}-\mathrm{H} \cdot \cdots \mathrm{S}=\mathrm{C}$ hydrogen bonds rather than the $\mathrm{N}-\mathrm{H} \cdots \cdot \mathrm{O}-\mathrm{C}$ hydrogen bonds that connect the pairs in form I (Fig. 3a). This arrangement of hydrogen bonds causes 1-dimensional parallel chains of TM molecules.

The solvent molecules are situated in channels between 355 chains of TM molecules (Fig. 3b). The distance between the closest aromatic $\mathrm{H}$ atoms and the $\mathrm{Cl}$ atoms in the DCM structure is approximately $3.07 \AA$, which indicates a weak

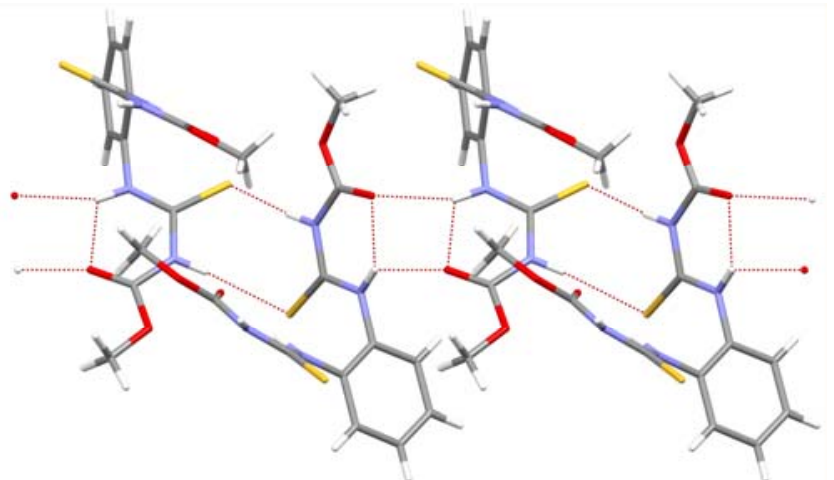

Fig. 4 One-armed chain of TM molecules (from the methanol solvate) connected by $\mathrm{N}-\mathrm{H} \cdot \bullet \mathrm{S}=\mathrm{C}$ and $\mathrm{N}-\mathrm{H} \cdot \bullet \mathrm{O}=\mathrm{C}$ hydrogen bonds. Non $\mathrm{H}-$ bonding hydrogens are omitted for clarity. interaction. The $\mathrm{C}-\mathrm{H}$ hydrogen atoms of the solvent molecules in the DCM structure are also weakly hydrogen bonded to the 360 sulfur atoms of TM with C $\cdots$. S distances of $3.68 \AA$ and $3.93 \AA$ and angles of $156^{\circ}$ and $173^{\circ}$, respectively.

\section{One-armed chains}

The methanol, ethanol, acetone and THF solvates crystallize in the triclinic space group P-1 with two TM molecules in the 365 asymmetric unit. The cyclohexanone solvate also crystallizes in the spacegroup P-1, but with four TM molecules in the asymmetric unit, whereas the DMSO solvate crystallizes in the monoclinic space group $\mathrm{C} 2 / \mathrm{c}$ with one $\mathrm{TM}$ molecule in the asymmetric unit. In these solvates the main arrangement of 370 hydrogen bonding is one where the molecules of TM arrange in chains, which include hydrogen bonds mainly to one arm of the molecules (Fig. 4 and ESI). Two types of hydrogen bond arrangements build up these chains, of which one is composed of two $\mathrm{N}-\mathrm{H} \cdots \mathrm{S}=\mathrm{C}$ hydrogen bonds and the other of two N$375 \mathrm{H} \cdot \bullet \mathrm{O}=\mathrm{C}$ hydrogen bonds between the molecules.

Though the hydrogen bonding pattern of the chains is the same for all the solvates with one-armed chains, the orientation of the molecules in the chains is different due to the inclusion of different solvent molecules. The methanol, 380 ethanol and acetone solvate structures are nearly isomorphic and the cyclohexanone solvate structure is most similar with them. The THF and DMSO solvate structures are quite different from the rest and each other. The variance in the orientation of TM molecules in the chains is most apparent in 385 the angles of the $\mathrm{N}-\mathrm{H} \cdots \mathrm{S}=\mathrm{C}$ hydrogen bonds (see ESI for hydrogen bonding parameters of all the solvates). 

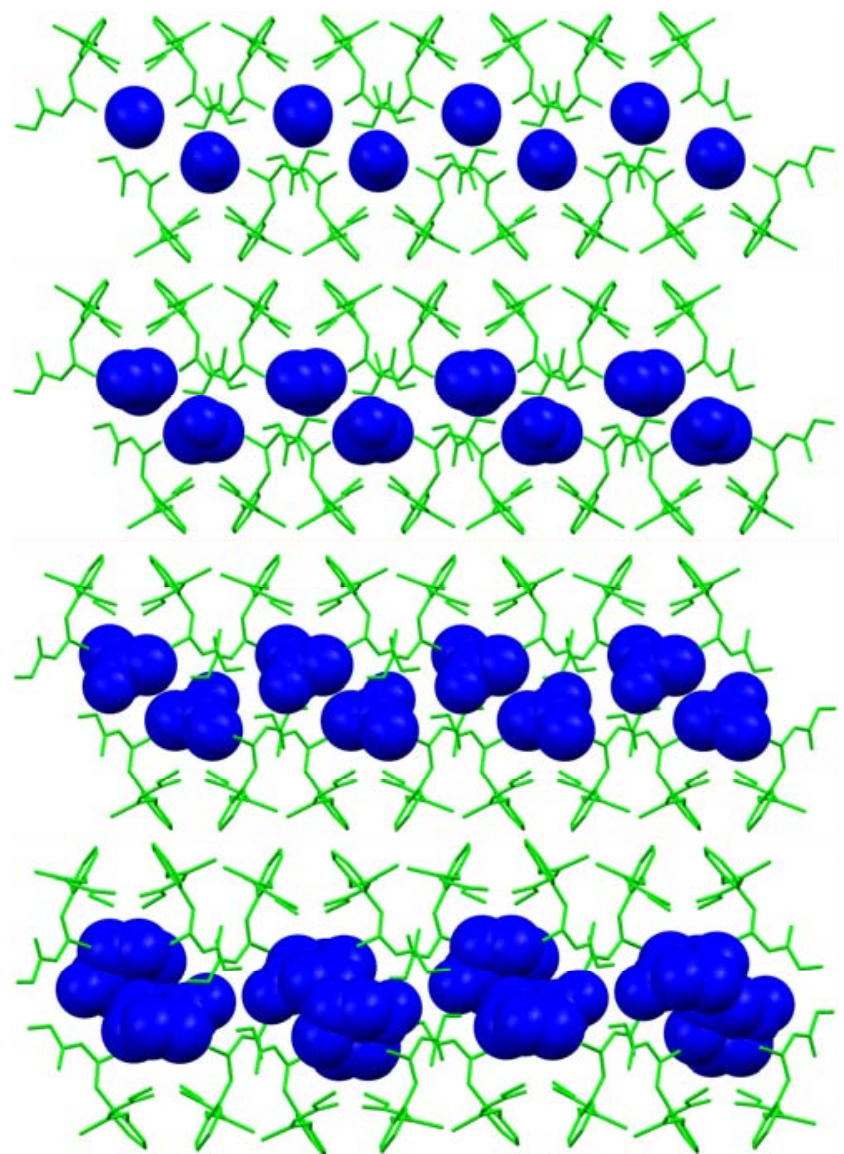

Fig. 5 Two-dimensional sheets in the methanol, ethanol, acetone and cyclohexanone solvates. Non H-bonding hydrogens are omitted for clarity.

The arm of the TM molecules that does not build up the one-armed chains is involved in hydrogen bonding to the solvent molecules and/or in direct hydrogen bonding between 390 adjacent chains (see ESI for pictures). In the methanol and ethanol solvates the chains are connected through two N$\mathrm{H} \cdot \cdots \mathrm{S}=\mathrm{C}$ hydrogen bonds between $\mathrm{TM}$ molecules and through

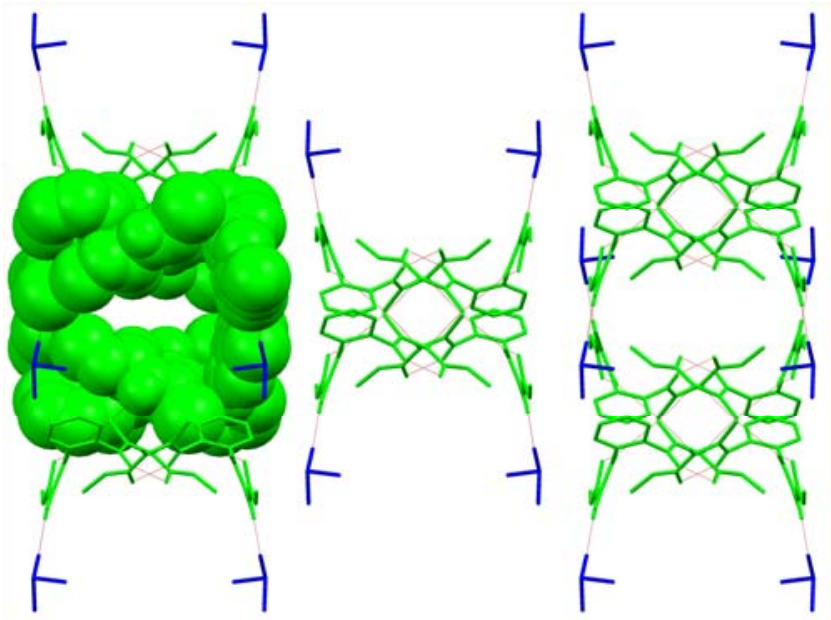

Fig. 7 DMSO solvate from one side showing the role of the ordered DMSO molecules and the channels for disordered DMSO molecules. Non $\mathrm{H}$-bonding hydrogens are omitted for clarity.

hydrogen bonding to the solvent molecules, which act as both a hydrogen bond donor and acceptor. In the acetone and 395 cyclohexanone solvate, the chains are connected with bifurcated hydrogen bonding through the solvent molecules and in the cyclohexanone solvate additionally with $\mathrm{N}-\mathrm{H} \cdot \cdots \mathrm{O}-\mathrm{C}$ hydrogen bonds between the TM molecules.

In the methanol, ethanol, acetone and cyclohexanone 400 solvates the connected chains build up two-dimensional sheets composed of solvent molecules in between two layers of TM molecules (Fig. 5). These sheets then stack up on each other, being the cause for the plate-like habit of the crystals.

The THF and chloroform solvates are isomorphic with each 405 other (Fig. 6a and b). The difference between the two is the ability of the THF molecule to form hydrogen bonds with TM and in the chloroform solvate the parallel one-armed chains are connected through hydrogen bonding via an arrangement of two $\mathrm{N}-\mathrm{H} \cdots \mathrm{S}=\mathrm{C}$ hydrogen bonds but in the THF solvate 410 they are not. These two solvates have a 1 to 1 ratio of TM to solvate unlike the other solvates with the same one-armed

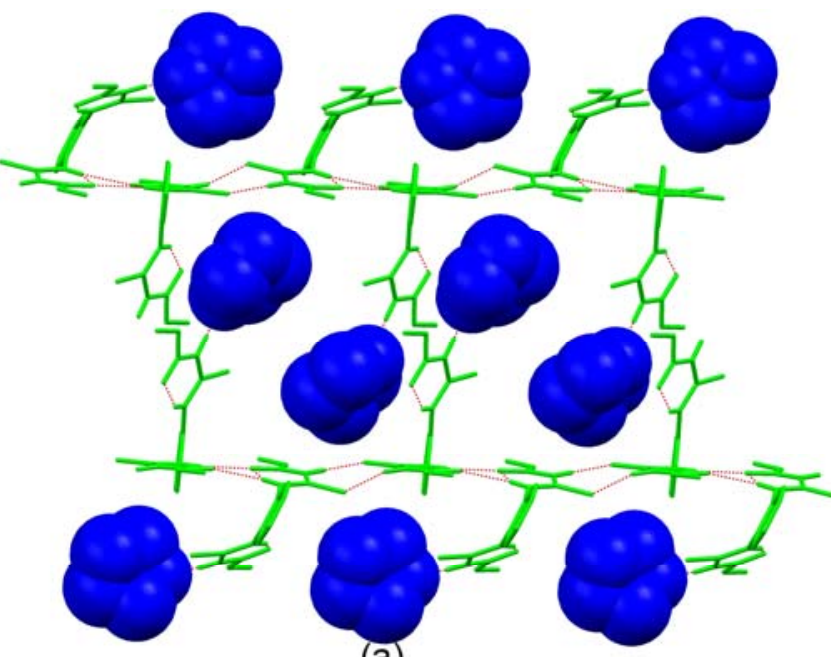

(a)

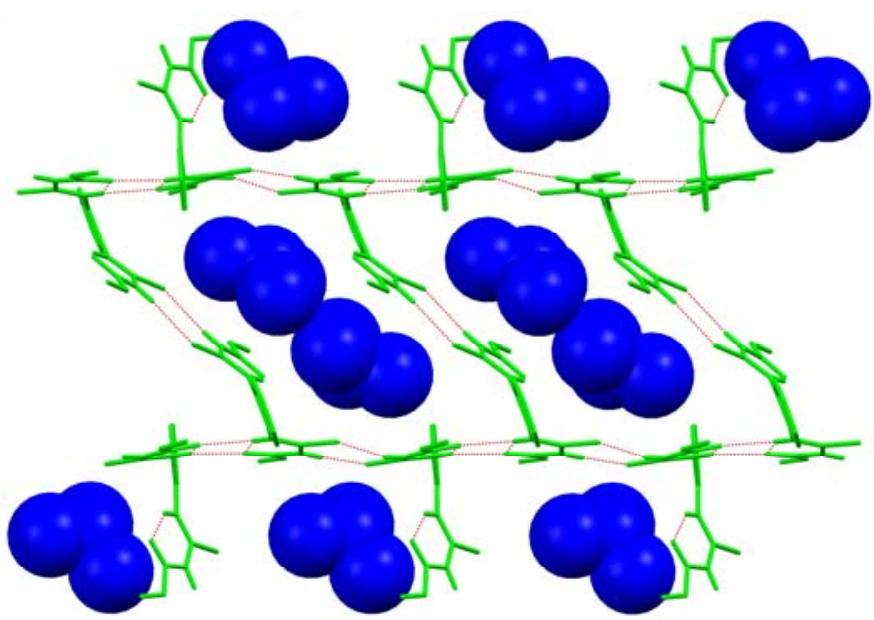

(b)

Fig. 6 Parallel packing of chains of the (a) THF solvate and the (b) chloroform solvate with solvent molecules in spacefill style. Non H-bonding hydrogens are omitted for clarity. 


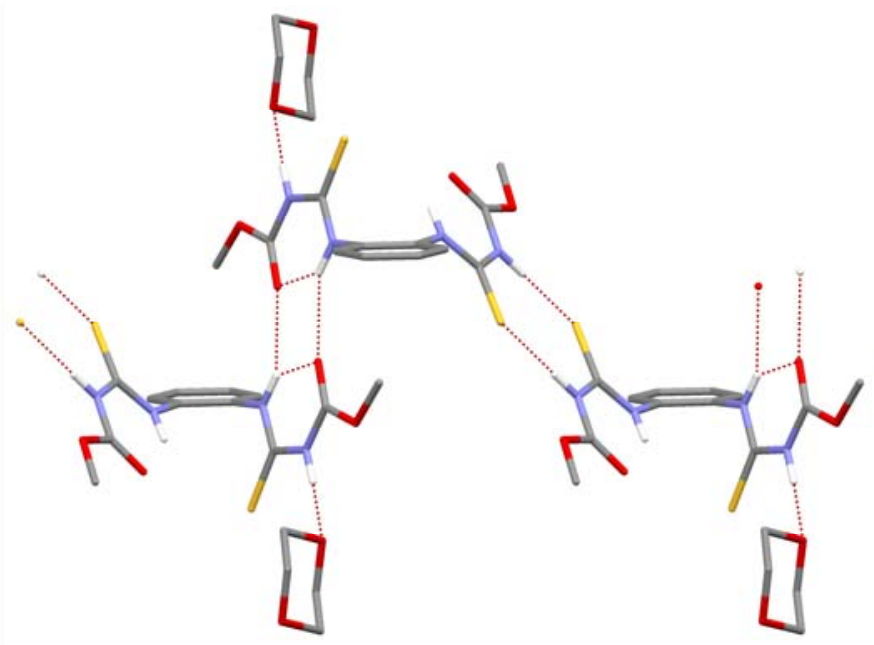

(a)

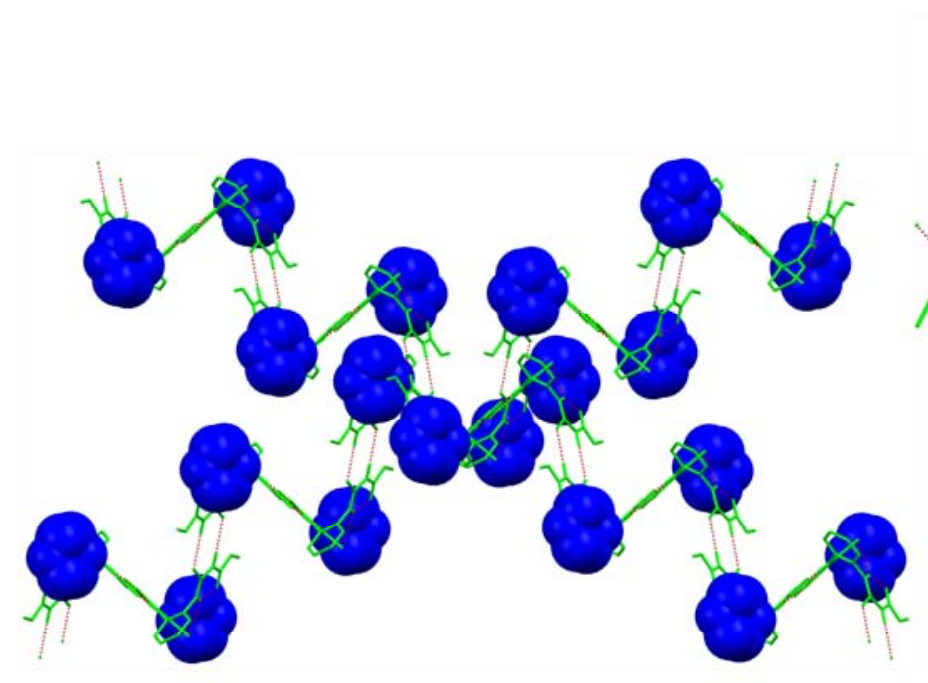

(c)
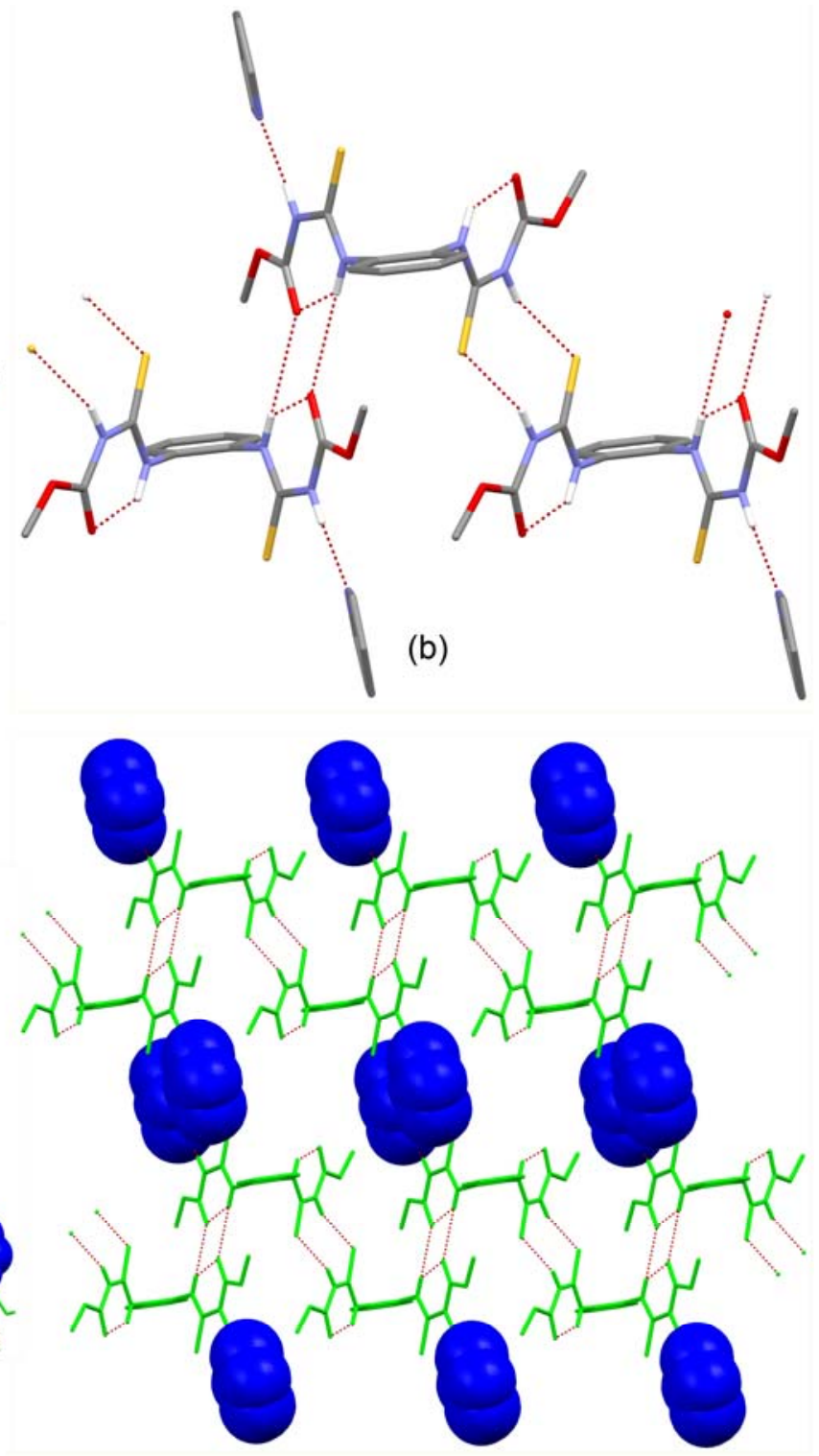

(d)

Fig. 8 Two-armed chains of TM molecules from the (a) dioxane and (b) pyridine solvates and (c) crossing chains of the dioxane solvate and (d) parallel chains of the pyridine solvate viewed down the crystallographic a-axis with solvent molecules in spacefill style. Non H-bonding hydrogens are omitted for clarity.

chain hydrogen bonding arrangement of TM molecules.

In the DMSO solvate the one-armed chains, which pack parallel to each other, are not connected through hydrogen 415 bonding. The severely disordered DMSO molecules in the DMSO solvate are placed in cavities that are lined up to form small tubular channels running through the crystal. These channels can be seen between the parallel chains when viewed from the side (Fig. 7). No hydrogen bond donors of the TM 420 molecules point into these cavities and it is likely that the disordered DMSO molecules are merely co-crystallized to fill the empty space. The analysis of the removed electron density supports the hypothesis of having eight disordered DMSO molecules in the unit cell making the TM to solvent ratio 1:2.

\section{Two-armed chains}

The dioxane and pyridine solvates crystallize in the monoclinic space group $\mathrm{C} 2 / \mathrm{c}$ and the triclinic space group $\mathrm{P}$ -
1 , respectively, but the hydrogen bonding pattern of the TM molecules in these solvates is the same. The molecules of TM 430 build up chains with arrangements of two $\mathrm{N}-\mathrm{H} \cdot \bullet \mathrm{S}=\mathrm{C}$ hydrogen bonds and two $\mathrm{N}-\mathrm{H} \cdot \cdots \mathrm{O}=\mathrm{C}$ hydrogen bonds involving both the arms of the molecule (Fig. 8a and b). Again as for the one-armed chains, the $\mathrm{N}-\mathrm{H} \cdot \cdots \mathrm{S}=\mathrm{C}$ hydrogen bonds show more variability in angles than the $\mathrm{N}-\mathrm{H} \cdot \bullet \mathrm{O}=\mathrm{C}$ hydrogen 435 bonds with the hydrogen bonds in the pyridine solvate being somewhat longer than those in the dioxane solvate.

In the pyridine solvate the chains arrange parallel to each other and in the dioxane solvate they cross each other (Fig. 8c and $\mathrm{d}$ ). In the pyridine solvate the pyridine molecules are 440 located in channels running down the crystallographic a-axis (Fig. 8d). In the dioxane solvate there are no specific channels where the dioxane molecules reside, but they are located 


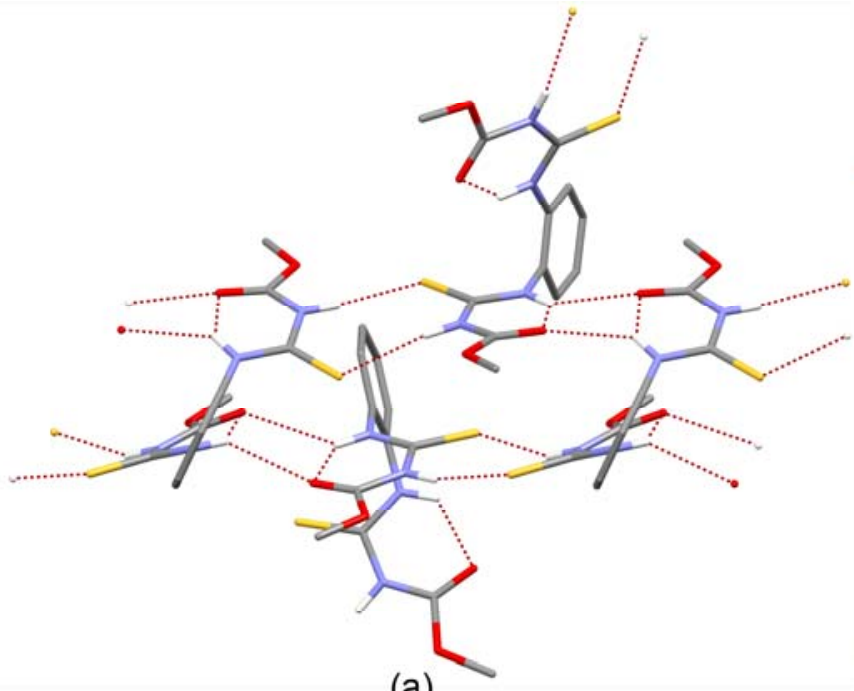

(a)

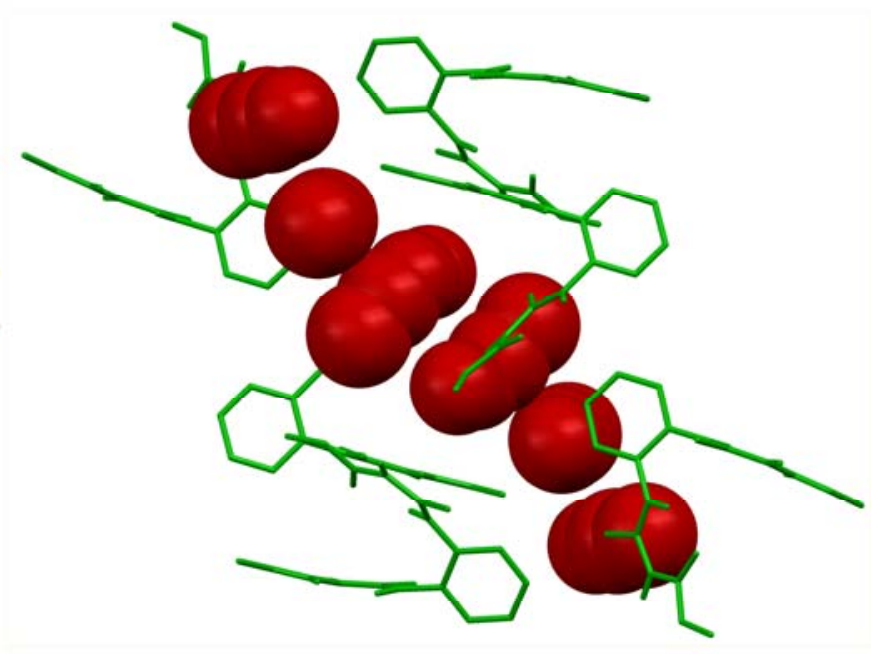

(b)

Fig. 9 (a) The hydrogen bonding arrangement and (b) the solvent channels in the $\mathrm{MeCN}$ solvate. Non H-bonding hydrogens are omitted for clarity.

pairwise in cavities in the structure.

\section{Acetonitrile solvate mono hydrate}

445 The acetonitrile solvate mono hydrate crystallized from a $1: 1$ $(\mathrm{V}: \mathrm{V})$ acetonitrile:water solution in the triclinic space group $\mathrm{P}-1$ and in addition to acetonitrile there is a molecule of water in the asymmetric unit in addition to three TM molecules, 2 $\mathrm{MeCN}$ molecules and one MeCN molecule with a population 450 density of 0.5 . No solvate with acetonitrile without water or vice versa could be crystallized despite many attemps.

The hydrogen bonding arrangement is a combination of the arrangements in the one-armed and two-armed chains and mostly similar to that in form II with double chains composed 455 of hydrogen bonding arrangements with two $\mathrm{N}-\mathrm{H} \cdots \mathrm{S}=\mathrm{C}$ or two $\mathrm{N}-\mathrm{H} \cdots \mathrm{O}=\mathrm{C}$ hydrogen bonds (Fig. 9a). The solvent molecules are located in channels (Fig. 9b) and hinder the formation of intact two-dimensional sheets like those in form II. The acetonitrile solvate mono hydrate could, in fact, be a 460 means to the crystallization of form II as they crystallized from the same solution (different flasks).

\section{Aromatic solvate structures}

The structures of the aromatic solvates, 1,2-DCB and benzene, are considerably different from those of the other solvates and 465 also from each other. In addition to varying hydrogen bonding (see ESI for hydrogen bonding parameters), the conformation of the molecules of TM is also somewhat different in the structures of the 1,2-DCB and the benzene solvate.

The 1,2-dichlorobenzene solvate crystallizes in the triclinic 470 space group P-1 with one molecule of TM and one molecule

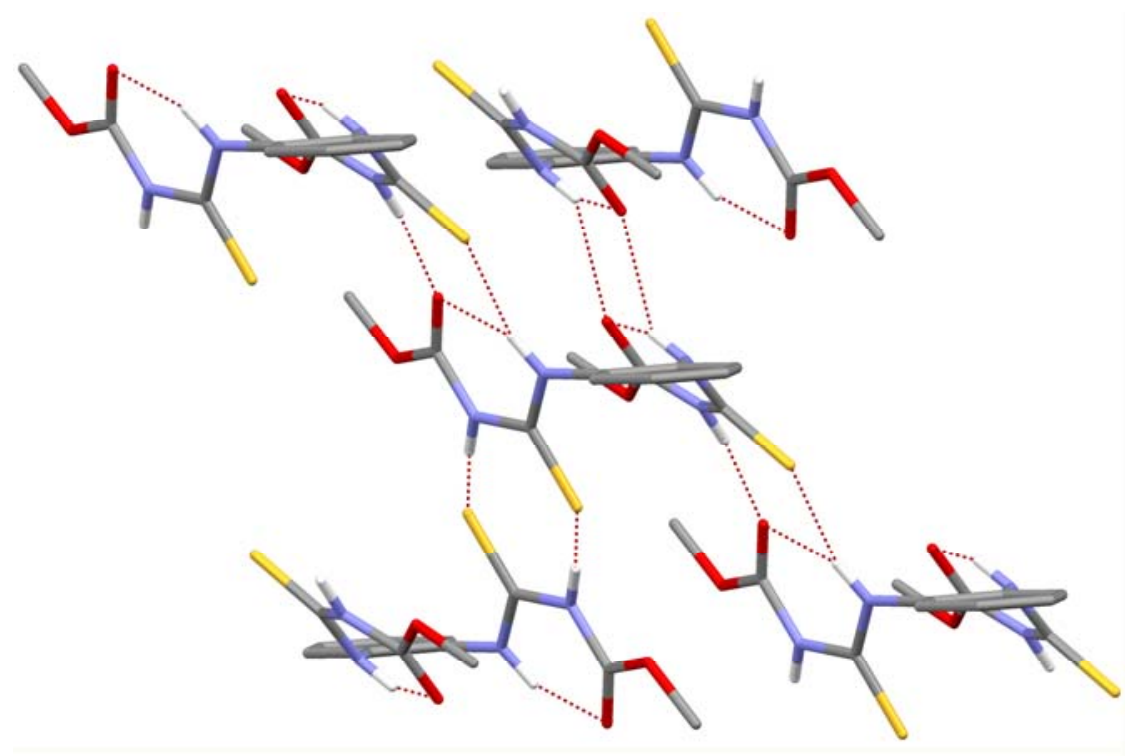

(a)

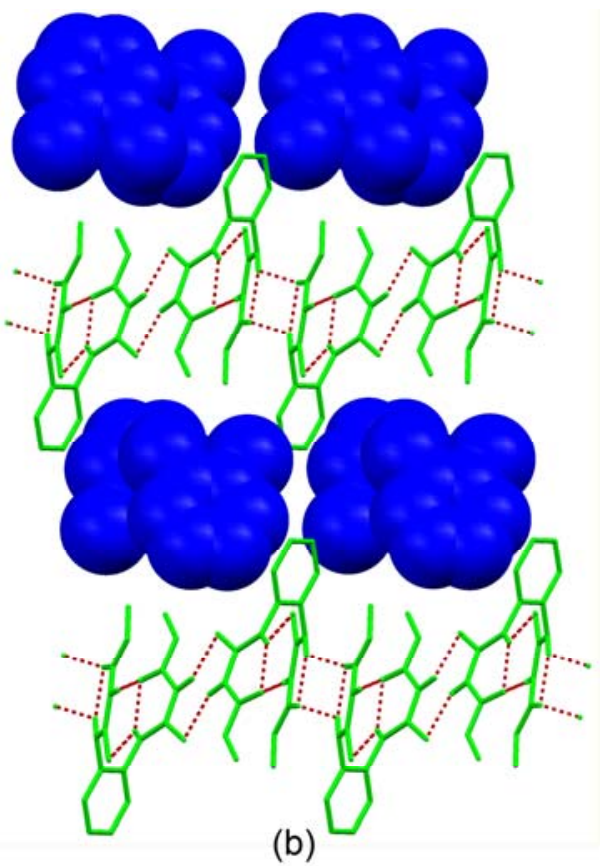

Fig. 10 (a) Hydrogen bonding in the 1,2-DCB solvate and (b) packing of the 1,2-DCB solvate sheets with 1,2-DCB molecules in spacefill style. Non Hbonding hydrogens are omitted for clarity. 


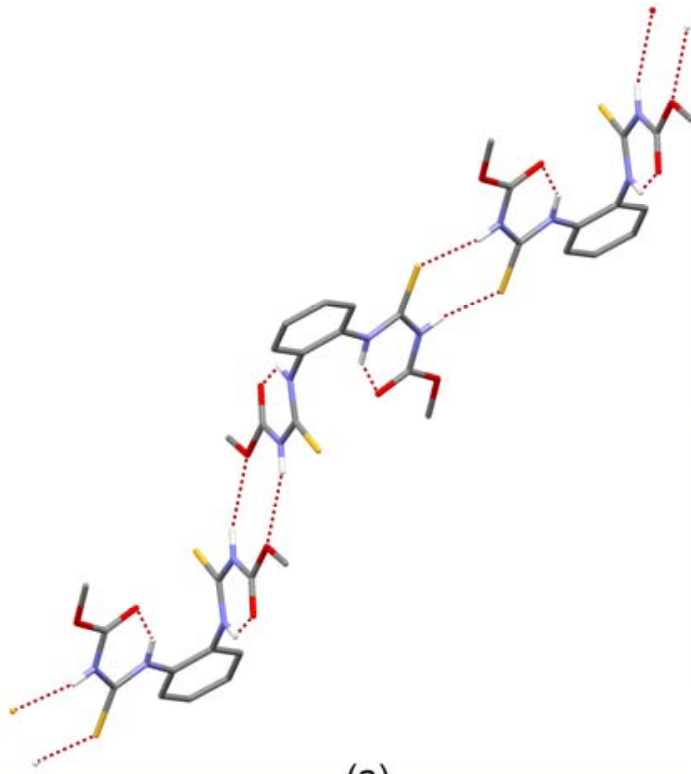

(a)

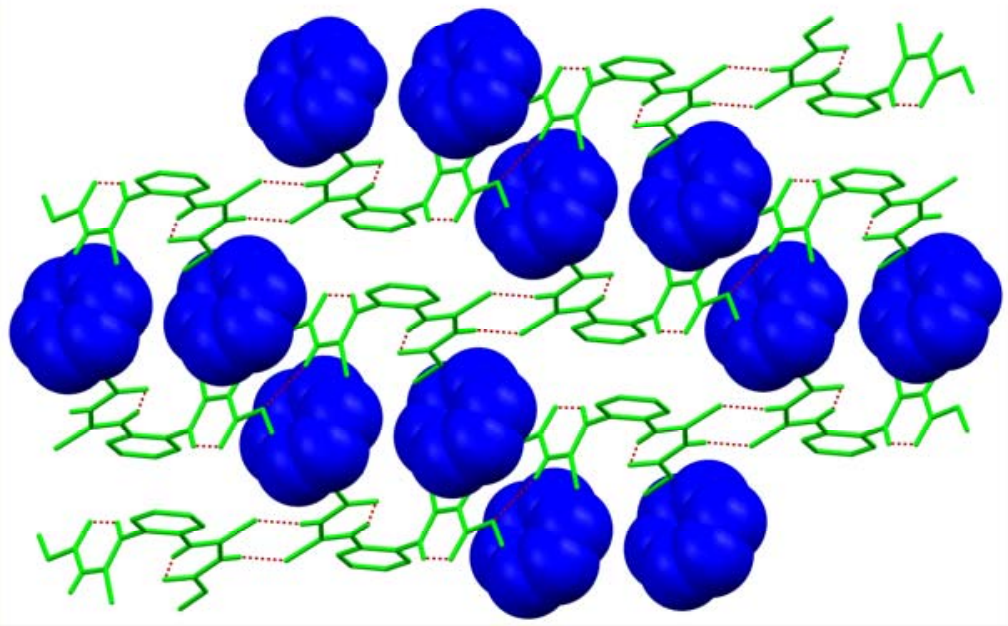

(b)

Fig. 11 (a) Chains of TM molecules and (b) the packing of the chains (with benzene molecules in spacefill style) in the benzene solvate. Non H-bonding hydrogens are omitted for clarity.

of solvent in the asymmetric unit. The arrangement of the TM molecules in the 1,2-DCB solvate resembles that in form II except there are three instead of two hydrogen bond arrangements building up the structure and the conformation

475 of the TM molecule is different. One of the hydrogen bonding arrangements consists of two $\mathrm{N}-\mathrm{H} \cdots \mathrm{S}=\mathrm{C}$ hydrogen bonds, another of two $\mathrm{N}-\mathrm{H} \cdots \mathrm{O}=\mathrm{C}$ hydrogen bonds and the third of one $\mathrm{N}-\mathrm{H} \cdots \mathrm{S}=\mathrm{C}$ hydrogen bond and one $\mathrm{N}-\mathrm{H} \cdots \cdot \mathrm{O}=\mathrm{C}$ hydrogen bond (Fig. 10a).

480 The hydrogen bonding arrangements make up twodimensional sheets of TM that stack up on each other, separated by the 1,2-DCB molecules (Fig. 10b). The benzene and methyl groups of TM protrude to both sides of the sheets, and aromatic interactions and weak $\mathrm{C}-\mathrm{H} \cdot \cdots \mathrm{Cl}$ hydrogen bonds

485 are expected between these groups and the 1,2-DCB molecules.

The hydrogen bonding in the benzene solvate structure is not similar to other structures because of $\mathrm{N}-\mathrm{H} \cdot \cdots \mathrm{O}-\mathrm{C}$ hydrogen bonds which are otherwise only found in form I and in the 490 cyclohexanone solvate in combining the chains. A pair of these $\mathrm{H} \cdots \mathrm{O}-\mathrm{C}$ hydrogen bonds and a pair of $\mathrm{N}-\mathrm{H} \cdots \mathrm{S}=\mathrm{C}$ hydrogen bonds build up chains of TM molecules (Fig. 11a). The distance between the sulfur, that is not hydrogen bonded to an amine hydrogen, and the methyl carbon is $3.732 \AA$ 495 which points toward possible weak $\mathrm{C}-\mathrm{H} \cdots \mathrm{*} \mathrm{S}=\mathrm{C}$ hydrogen bonding interactions. The chains pack parallel to each other with the benzene molecules in channels running through the structure (Fig. 11b).

\section{Summary of the structures}

500 There are interesting similarities and differences in the hydrogen bonding arrangements and the conformations of the TM molecules in the sixteen described structures. These will be summarized here and the calculated gas phase conformers will also be looked at briefly.

This journal is (c) The Royal Society of Chemistry [year]

\section{${ }_{505}$ Hydrogen bonding arrangements}

The TM molecule has six possible hydrogen bond acceptors (two ester groups with two oxygen acceptors and two sulfur acceptors) and four amine hydrogens as possible hydrogen bond donors. This causes a number of possible intra- and 510 intermolecular hydrogen bonding arrangements, many of which are exhibited in the described structures.

The main hydrogen bonding arrangements seem to be pairs of $\mathrm{N}-\mathrm{H} \cdots \cdot \mathrm{O}=\mathrm{C}$ and $\mathrm{N}-\mathrm{H} \cdots \mathrm{S}=\mathrm{C}$ hydrogen bonds, but the handin-hand pairing of TM molecules found in form I and the 515 DCM and 1,2-DCE solvates seems to be favorable enough to bring about the formation of the weaker $\mathrm{N}-\mathrm{H} \cdots \mathrm{O}-\mathrm{C}$ hydrogen bond paired to a $\mathrm{N}-\mathrm{H} \cdot \cdots \mathrm{O}=\mathrm{C}$ hydrogen bond in the most stable form I, leaving a sulfur acceptor unused. Interestingly, in the benzene solvate pairs of $\mathrm{N}-\mathrm{H} \cdot \cdots \mathrm{O}-\mathrm{C}$ hydrogen bonds seem to

520 be favored, leaving the $\mathrm{C}=\mathrm{O}$ groups to hydrogen bond only intramolecularly and half the sulfur acceptors unused. Mixed pairs of one $\mathrm{H} \bullet \bullet \mathrm{O}=\mathrm{C}$ and one $\mathrm{N}-\mathrm{H} \cdots \mathrm{S}=\mathrm{C}$ hydrogen bond are found only in the 1,2-DCB solvate and form I.

\section{Conformations}

${ }_{525}$ The arms of the TM molecules are fairly planar in all structures due to intramolecular $\mathrm{N}-\mathrm{H} \cdot \bullet \mathrm{O}=\mathrm{C}$ hydrogen bonds between $\mathrm{N} 2$ and $\mathrm{O} 1$, and $\mathrm{N} 3$ and $\mathrm{O} 3$ (the numbering of atoms is in Fig. 1).The conformations of the molecules are thus described by comparing the position of the arms of the 530 molecules in respect to the plane of the benzene ring.

As can be seen in Figure 12 a-d, the two polymorphs, form I (Fig. 12a) and form II (Fig. 12b), represent not only different hydrogen bonding, but also conformational polymorphism and, moreover, different conformers of TM are also observed 535 in the solvate structures. The most remarkable difference in between form I and form II is that, unlike form II, form I has an intermolecular $\mathrm{N}-\mathrm{H} \cdots \mathrm{S}=\mathrm{C}$ hydrogen bond connecting the two arms of the molecule in addition to the above mentioned $\mathrm{N}-\mathrm{H} \cdot \bullet \mathrm{O}=\mathrm{C}$ hydrogen bonds within the arms of the molecule. ${ }_{540}$ Interestingly, the acetonitrile/water solvate, with $Z^{\prime}=3$, has 


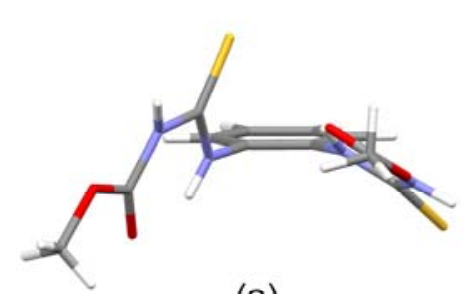

(a)

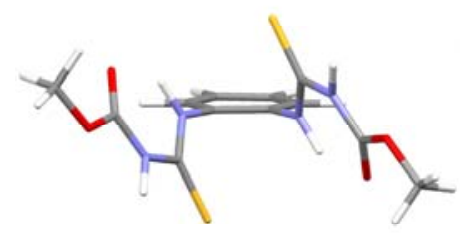

(e)

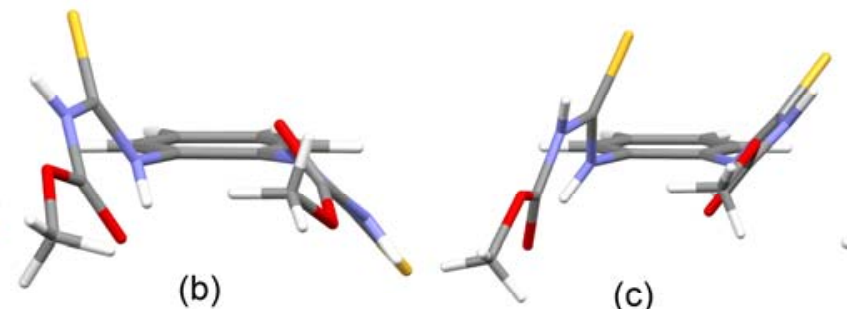

(c)

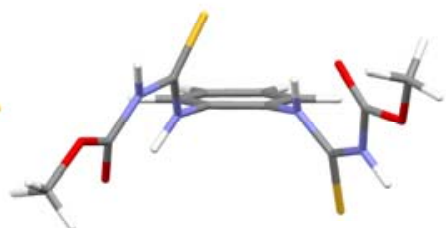

(g)

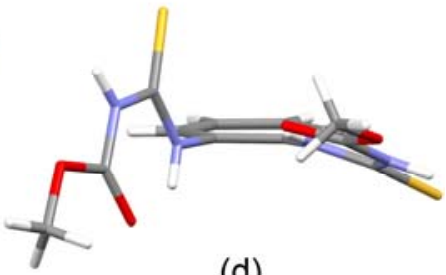

(d)

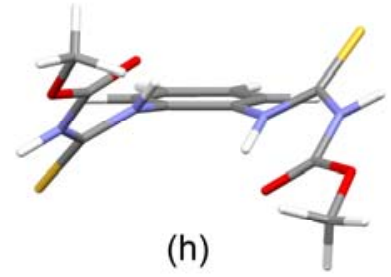

Fig. 12 Conformations of the TM molecules in (a) form I, (b) form II, (c) the 1,2-DCB and (d) benzene solvates and the four calculated gas phase conformers with the lowest energy (e) $\Delta \mathrm{E}=0 \mathrm{~kJ} / \mathrm{mol}$ (f) $\Delta \mathrm{E}=3.22 \mathrm{~kJ} / \mathrm{mol}$ (g) $\Delta \mathrm{E}=5.40 \mathrm{~kJ} / \mathrm{mol}$ (h) $\Delta \mathrm{E}=7.57 \mathrm{~kJ} / \mathrm{mol} \mathrm{viewed} \mathrm{roughly} \mathrm{down} \mathrm{the} \mathrm{plane} \mathrm{of}$ the benzene ring.

one of the three independent TM molecules in a confomation like that in form II and the other two more like that in form I, but not close enough as to have an intermolecular $\mathrm{N}-\mathrm{H} \cdot \bullet \mathrm{S}=\mathrm{C}$ hydrogen bond $(\mathrm{N}-\mathrm{H} \cdots \cdot \mathrm{S}=\mathrm{C}$ distance approximately $3.1 \AA$ in ${ }_{545}$ comparison to $2.7 \AA$ in form I).

Calculations of the gas phase conformers of TM were done in order to get insight about the relative energies of the found conformers. Relative to the conformer with the lowest calculated energy, there are six conformers with a $\Delta \mathrm{E}$ less 550 than $20 \mathrm{~kJ} / \mathrm{mol}$ and a total of 214 with a $\Delta \mathrm{E}$ less than 100 $\mathrm{kJ} / \mathrm{mol}$. The six lowest energy conformers thus lie in an energy range comparative to one moderately strong hydrogen bond. The four most stable conformers $(\Delta \mathrm{E}$ less than $8 \mathrm{~kJ} / \mathrm{mol}$, Fig. 12e-h) all have the intramolecular $\mathrm{N}-\mathrm{H} \cdot \cdots \mathrm{O}=\mathrm{C}$ hydrogen 555 bond that is seen in all of the crystal structures. In conformations with higher energy this bond can be changed into a $\mathrm{N}-\mathrm{H} \cdots \mathrm{O}-\mathrm{C}$ hydrogen bond, and in even higher energy conformers an arm of the TM molecules can be twisted into a non-planar conformation with no intra-molecular hydrogen 560 bonding, making these higher energy conformations unlikely in crystals structures.

The conformers observed in the crystal structures have varying torsion angles between the plane of the benzene ring and the arms of the molecules with the gas-phase minimized

565 state and direct comparison is not feasible. For example, the most stable gas phase conformer (Fig. 12e) has no good matches in the determined crystal structures, though one of the TM molecules in the $\mathrm{MeCN} / \mathrm{H}_{2} \mathrm{O}$ solvate comes close. The second conformer (Fig. 12f) resembles that in the benzene 570 solvate (Fig. 12d). The third gas-phase conformer (Fig. 12g) is quite like that in many of the solvate crystal structures and form I, but most closely resembles the TM molecules in the THF and cyclohexanone solvates. The fourth conformer (Fig. 12h) resembles most closely that in form II of TM (Fig. 12b).

575 The aromatic solvates have conformations of TM most unlike those in the other structures. In the benzene solvate one arm of the molecule is more in the plane of the benzene ring whereas the other arm is, conversely, less in the plane of the benzene ring than in form I. Further, the conformation of TM 580 in the 1,2-DCB solvate (with sulfur atoms on the same side of the aromatic plane) was not found among the gas phase conformers. In this structure the planes of the arms of the TM molecules are almost parallel to each other, which is also the case in form II, and enables the formation of the similar 585 hydrogen bonded sheet arrangements in the structures.

A lattice energy analysis and a constrained energy optimization of the observed crystal structure conformers is left out of this study as the authors do not expect that such an analysis would bring more essential information. It is, 590 however, clear that the variability of the conformations of TM in the solved crystal structures is paralleled by a number of gas phase conformers with small energy differences and this flexibility probably accounts for the large number of solvates of TM.

\section{${ }_{595}$ Conclusions}

TM was found out to exists in two polymorphic forms which have very similar melting points. The original and known form $\mathrm{I}$ is the thermodynamically most stable form, which is monotropically related to Form II. Form II can be accessed via 600 desolvation of various different solvate forms.

The discovery of a series of fourteen solvates and the structure determination of these via single crystal X-ray measurement is the highlight of this work. Solvent molecules capable of forming hydrogen bonds (acting either as hydrogen ${ }_{605}$ bond acceptors or both acceptor and donor) presented the majority, but also other, such as 1,2-dichlorobenzene and benzene were among solvate forming solvents. The isostructural methanol and ethanol solvates, with desolvation points around $140^{\circ} \mathrm{C}$, were remarkably stable against 610 desolvation, whereas the non-hydrogen bonded solvates solvated already at ambient conditions.

The single crystal structures reported here represent a variety of interaction possibilities of TM varying from hydrogen 
bonding to aromatic and lipophilic interactions. No clear 615 patterns in packing or formation could be drawn from the structures. It is however noteworthy that TM has a large amount of low energy conformers and several possibilities of forming hydrogen bonds. These two facts can as tradeoff, lead to new hydrogen bonding and close packing modes and can 620 reduce the total energy difference between alternate crystal structures. The search in the CSD by van de Streek $^{32}$ shows that there are only a few compounds, many of which are not organic neutral compounds of the size of TM, with ten or more solvate structures reported. It is very likely that, similar 625 to sulfathiazole with its over one hundred solvates ${ }^{33}$, several new solvates and also co-crystals with a variety of different functional groups could be found for TM.

As shown in this paper, crystallographical methods play a key role in studying polymorphism and solid state structures. ${ }_{630}$ However, also all the used spectroscopical methods $\left({ }^{13} \mathrm{C}\right.$ CP/MAS NMR, IR and Raman) are usefull in identifying the polymorphic forms of TM from each other and can be valuable in cases where crystallographical methods are not available or can not be applied. Thermoanalytical methods are 635 also especially helpful in determining the stability of a new modification and resolving whether it is a solvate or not.

\section{Acknowledgements}

We kindly thank Mr. Wolfgang Houy (BASF SE) for carrying out most of the single crystal structure measurements and ${ }_{640}$ Spec. Lab. Technician Reijo Kauppinen (University of Jyväskylä) for his help in running the ${ }^{13} \mathrm{C}$ CP/MAS NMRspectra. We also thank the academy of Finland (proj. no. 116503 ) for partly funding the work.

\section{Notes and references}

${ }_{645} 1$ D. Braga, G.R. Desiraju, J.S. Miller, A.G. Orpen and S.L. Price, CrystEngComm, 2002, 4, 500 - 509.; P. Erk, H. Hengelsberg, M. F. Haddow, R. Van Gelder, CrystEngComm, 2004, 6, 474-483.; G. R. Desiraju, Angew. Chem. Int. Ed., 2007, 46, 8342-8356.

2 G. R. Desiraju, Angew. Chem. Int. Ed. Engl., 1995, 34, 2311-2327.

6503 J. Bernstein, Polymorphism in Molecular Crystals, Oxford University Press, United States, 2002; H. G. Brittain, Polymorphism in Pharmaceutical Solids, Marcel Dekker, Inc., New York, USA, 1999.; U. J. Griesser, in Polymorphism in the Pharmaceutical Industry, ed. R. Hilfiker, WILEY-VCH Verlag GmbH \& Co. KGaA, Weinheim, Germany, 2006, pp.211-234.

4 C.H. Görbitz and H.-P. Hersleth, Acta Cryst., 2000, B56, 526-534.; R. Banerjee, P. M. Bhatt and G. R. Desiraju, Cryst. Growth Des., 2006, 6, 1468-1478.; S. A. Barnett, D. A. Tocher and M. Vickers, CrystEngComm, 2006, 8, 313-319.; K. Jarring, T. Larsson, B. Stensland and I. Ymén, J. Pharm. Sci., 2006, 95, 1144-1161.; T. Hosokawa, S. Datta, A.R. Sheth, N.R. Brooks, V.G. Young and D.J.W. Grant, Cryst. Growth Des., 2004, 4, 1195.

5 D.D Wirth and G.A. Stephenson, Org. Process Res. Dev., 1997, 1, 55-60.; J. Bauer, J. Morley, S. Spanton, F.J.J. Leusen, R. Henry, S.

${ }_{665}$ Hollis, W. Heitmann, A Mannino, J. Quick, W. Dziki, J. Pharm. Sci., 2006, 95, 917-928.

6 C.H Price, G. D. Glick and A. J. Matzger, Angew. Chem. Int. Ed., 2006, 45, 2062-2066.

7 A. Nangia, Acc. Chem. Res., 2008, 41 (5), 595-604.

6708 U.J. Griesser; D. Weigand, J. M. Rollinger, M. Haddow and E. Gstrein, J. Therm. Anal. Cal., 2004, 77, 511-522.; D. Chopra, T. P. Mohan, K. Sundaraja Rao and T. N. Guru Row, CrystEngComm, 2005, 7, 374-379.
9 GB Pat., 1307 250, 1970.; GB Pat., 1313 966, 1970.; US Pat., 3852 278, 1973.

10 WO 2008/096005.

11 J. Dekker and S.G. Georgopoulos, Fungicide Resistance in Crop Protection, Centre for Agricultural Publishing and Documentation, Wageningen, Netherlands, 1982.

68012 C.S. Tomlin, The e-Pesticide Manual, Version 3.2 13, British Crop Production Council (BCPC), Great Britain, 2005.

13 G.K. Dixon, L.G. Copping and D.W. Hollomon, Antifungal Agents Discovery and Mode of Action, BIOS Scientific Publishers Ltd, Oxford, UK, 1995.

68514 G. M. Sheldrick, Acta Crystallogr. Sect. A., 2008, 64, 112-122.

15 R.H. Blessing, Acta Cryst., 1995, A51, 33.

16 Z. Otwinowski, D. Borek, W. Majewski and W. Minor, Acta Crystallogr. A., 2003, 59, 228-234.

17 L.J. Farrugia, WinGX, J. Appl. Cryst., 1999, 32, 837-838.

69018 SHELXTL Version 6.14., Bruker Analytical X-ray Solutions, 2000, Madison, Wisconsin, USA

19 P. van der Sluis and A.L. Spek, Acta Cryst., 1990, A46, 194-201.

20 C.F. Macrae, P.R. Edgington, P. McCabe, E. Pidcock, G.P. Shields, R. Taylor, M. Towler and J. van de Streek, Mercury 1.4.1, J. Appl. Cryst., 2006, 39, 453-457.

21 S. L. Mayo, B.D. Olafson, W.A. Goddard III, J. Phys. Chem., 1990, 94, 8897.

22 A. K. Rappe, W.A. Goddard III, J. Phys. Chem., 1991, 95, 3358

23 Cerius $^{2}$ V4.6, Accelrys Inc., 2001, San Diego

70024 A. D. Becke, Phys. Rev. A, 1988, 38, 3098; J. P. Perdew, Phys. Rev. B, 1986, 33, 8822; J. P. Perdew, Phys. Rev. B, 1986, 34, 7406(E).

25 A. Schäfer, C. Huber, R. Ahlrichs, J. Chem. Phys., 1994, 100, 5829.

26 K. Eichkorn, F. Weigend, O. Treutler, R. Ahlrichs, Theoret. Chim. Acta, 1997, 97, 119.

70527 F. Weigend, M. Häser, Theoret. Chim. Acta, 1997, 97, 331.

28 TZVPP is the acronym used in the Turbomole basis set library and denotes a valence triple-zeta basis set (TZV, see Ref. 23) augmented with Dunning's correlation consistent polarization functions (T. H. Dunning, Jr., J. Chem. Phys., 1989, 90, 1007; D. E. Woon, T. H. Dunning, Jr., J. Chem. Phys., 1993, 98, 1358.).

29 Turbomole V5.10, University of Karlsruhe 2008, www.turbomole.com

30 K. Masuda and F. Horii, Macromolecules, 1998, 31, 5810-5817.

31 A. Burger and R. Ramberger, Microchimica Acta, 1979, 72, 259-271; A. Burger and R. Ramberger, Microchimica Acta, 1979, 72, 273-316.

32 J. van de Streek, CrystEngComm, 2007, 9, 350 - 352.

33 A.L. Bingham, D.S. Hughes, M.B. Hursthouse, R.W. Lancaster, S. Tavener and T.L. Threlfall, Chem. Commun., 2001, 603-604. 